\title{
Review of vibration devices for vibration-assisted machining
}

\author{
Lu Zheng $^{1} \cdot$ Wanqun Chen ${ }^{2} \cdot$ Dehong Huo ${ }^{1}$
}

Received: 6 February 2020 / Accepted: 14 May 2020 / Published online: 29 May 2020

(C) The Author(s) 2020

\begin{abstract}
Vibration-assisted machining (VAM) is a process in which high-frequency small amplitude vibration is applied on tool or workpiece to improve cutting performance, especially for hard and brittle materials. It has been applied to several machining processes including drilling, turning, grinding, and milling. This paper offers a review for the vibration devices used in VAM process. The history and current status of the vibration devices are presented including the design theory and principles. The developed vibration devices are categorised in two groups, namely resonant and non-resonant modes. Advantages and limitations of these devices are summarized and discussed, including their development trend. In addition, the benefits and applications of vibration-assisted machining are also introduced.
\end{abstract}

Keywords Vibration assisted machining $(\mathrm{VAM}) \cdot$ Vibration devices $\cdot$ Resonant and non-resonant modes $\cdot$ Cutting performance

\section{Introduction}

Precision components are increasingly in demand in various engineering fields such as MEMS, electro-optics, aerospace, automotive, biomedical engineering, and ICT hardware. In addition to the aims of achieving tight tolerances and highquality surface finishes, many applications also require the use of hard and brittle materials such as optical glass and technical ceramics owing to their superior physical, mechanical, optical, and electronic properties. However, due to their high hardness and usually low fracture toughness, the processing and fabrication of these hard-to-machine materials have always been challenging. Efforts to enhance machining performance have revealed that machining quality can be improved using the high frequency vibration of the tool or workpiece. Vibrationassisted machining (VAM) was first introduced in the late 1950s, and has been applied in various machining processes, including both traditional machining (turning, drilling, grinding, and more recently milling) and non-traditional machining (laser machining, electro-discharge machining, and electro-

Dehong Huo

dehong.huo@newcastle.ac.uk

1 Mechanical Engineering, School of Engineering, Newcastle University, Newcastle upon Tyne NE1 7RU, UK

2 Centre for Precision Engineering, Harbin Institute of Technology, Harbin 150001, People's Republic of China chemical machining), and it is now widely used in the precision manufacturing of components made of various materials. Vibration-assisted machining adds external energy to the conventional machining process and generating high frequency, low amplitude vibration in the tool or workpiece, a periodic separation between the uncut workpiece, and the tool can be achieved. This can decrease the average machining forces and generate thinner chips, which in turn leads to high processing efficiency, longer tool life, better surface quality and form accuracy, and reduced burr generation [1-6]. Moreover, when hard and brittle materials, such as titanium alloy, ceramic, and optical glass, are involved, the cutting depth in the ductileregime cutting mode can be increased [7]. As a result, cutting performance can be improved and unnecessary postprocessing can be avoided, which allows the production of components with more complex shape features [8]. Nevertheless, there are still many opportunities for technological improvement and ample scope exists for better scientific understanding and exploration.

Well-designed vibration system plays an important role in the implementation of vibration-assisted machining. A typical vibration system consists of vibration sources (actuators), a vibration transmission/amplification mechanism, and a control system. Generally, the actuators and transmission/ amplification mechanisms selected to be complementary. Given that certain demands such as required vibration frequency and amplitude range are proposed in the design phase, the optimal overall device structure to match those demands is 
determined first. Then, the key structural parameters are optimized using the finite element analysis (FEA) method, and the corresponding dynamic and static characteristics can be obtained. As a result, these key values in turn influence the choice of the vibration actuators. According to the system's operating frequencies, these proposed vibration devices can be divided to two groups: the non-resonant mode and the resonant mode. The operating vibration frequency of a nonresonant vibration system is variable, except its natural frequency. In order to increase stability and reduce the dynamic error in the vibration stage, flexible hinge structures are widely used due to their superior dynamic response, low friction, and ease of control. For a resonant system, the working frequency is fixed at the natural frequency of the vibrator. A sonotrode (also called a horn or concentrator) vibrates at its natural frequency, transferring and amplifying a given vibration from a vibration source, which is usually a magnetostrictive or piezoelectric transducer. This system can achieve a higher operating frequency and greater energy efficiency compared with a non-resonant system. However, its vibration trajectory cannot be controlled precisely owing to the nature of resonant vibrations and the phase lag between excitation and the mechanical response. Compared with resonant systems, non-resonant systems tend to achieve higher vibration accuracy, and it is easier to achieve closed-loop control of the vibration trajectories under low-frequency conditions.

This paper reviews vibration systems, including actuator types and their selection, transmission/amplification mechanisms, and control system design. By analysing design theories and principles, the advantages and disadvantages of various types of vibration devices are discussed, and the development trend of vibration devices is also mentioned.

\section{Actuators}

As power output devices, actuators convert other types of energy into mechanical energy to drive the vibration stage. This not only contributes to the bandwidth of the vibration frequency and amplitude, but also to the accuracy of the motion of the vibration stage. Currently, two types of actuators, namely piezoelectric and megnetostrictive actuators, are mainly selected for vibration systems. This section provides a general understanding information about these actuators, including their strengths and weaknesses.

\subsection{Piezoelectric actuators}

Piezoelectric actuators apply the unique piezoelectric properties of piezoelectric ceramics to convert high-voltage electrical energy into mechanical energy for high-frequency vibration. Compared with other types of actuators, they have the characteristics of low cost, simple structure, small size, fast response, high control precision, the lack of magnetic field and electrical fields, and no electromagnetic interference or electromagnetic noise, improving system stability and leading to more flexible designs of vibration devices. Various types of piezoelectric actuators, including stacked, thin plate, tubular, and bimorph types, have been developed for different applications $[9,10]$. Considering factors such as displacement output, stiffness, and frequency response, stack-type piezoelectric actuators made of multiple pieces of piezoelectric ceramic plates mechanically connected in series and electrically connected in parallel are usually chosen in actual vibration systems.

\subsection{Magnetostrictive actuators}

In the 1960/1970s, the technology of PZT was not yet fully understood. And magnetostrictive actuators were the best choice for vibration devices. It applies a ripple voltage to the electromagnetic coil, and its electromagnetic force is used to cause the moving core to vibrate. Although electromagnetic vibrators are reliable source of vibration, the major drawback is low energy efficiency caused by high electrical eddy current losses. These electrical losses are transformed into heat and may damage the vibrator [11]. Therefore, with electromagnetic vibrators, the cooling issue always needs to be considered, leading to bulky size [12]. Currently, magnetostrictive actuators are usually applied in vibration systems which require low vibration frequency and large vibration amplitude.

\section{Transmission mechanisms}

Two mechanisms using either flexible hinges or an ultrasonic horn are mainly chosen in the design of vibration system. The history of flexible hinge structures can be trace to the 1960s. With the development of the aerospace and aviation sectors, the resolution and size of the support in order to achieve small deflection ranges no longer met the requirements. After exploring various types of elastic support tests, engineers gradually developed flexible hinges which were characterised by high resolution, small volume, and no mechanical friction or gaps. Currently, many types of flexible hinges, including circular, elliptical, square fillet, and single notch profiles, have been developed and are widely used to guide the displacement of vibration in the non-resonant vibration-assisted systems. In addition, they are often integrated into a double parallel or parallel four-bar linkage so as to reduce coupling motion, because the non-resonant vibration stage is usually designed to work in two or more dimensions [13]. The ultrasonic horn is an important component of a resonant vibration system. It is used to transmit the mechanical energy converted from electrical energy into the workpiece by the transducer. It is a stage 
of the mechanical amplification of the power ultrasonic amplitude to improve the ultrasonic processing efficiency.

\section{Drive and control}

Besides accuracy in the processing and assembly of mechanical components, the control strategy used also has a great influence on the motion accuracy of the vibration system. Generally, these control systems can be divided as open or closed loop systems. Due to the high working frequency involved, an open loop system is the first choice for a resonant vibration system. To build a proper open loop control system for a piezoelectric actuator, a mathematical model of the piezo-driven stage needs to be built first due to its hysteresis, and non-linear and creep properties. Many methods taking into account the intrinsic mechanism and dynamic properties of piezoelectric actuators have been developed in recent decades, including the Preisach, Maxwell, and Prandtl-Ishinskii models [14-16]. The reference is calculated from the corresponding control signal according to the reference input value, and it is sent to the piezoelectric actuator through a piezoelectric amplifier to generate a corresponding displacement. The features of open loop control system include a simple structure and ease of implementation; however, when the object or control device is disturbed or the characteristic parameters change during the working process, error cannot be compensated for this affects the accuracy of control. To overcome this drawback, closed loop control systems are used. Close loop control systems are mainly used in non-resonant vibration systems and an industry standard controller is required. The traditional PID control method algorithm has high control precision, but it is not suitable for uncertain time-varying systems. In contrast, fuzzy adaptive PID control can effectively identify the mathematical model of the controlled object, adjust the parameters and structure of the controller in real time according to given performance indicators, and reduce output error at this stage. However, close loop control systems always require high precision and resolution position sensors, which increases cost.

\section{Vibration-assisted machining systems}

As mentioned previously, vibration-assisted machining systems can be divided into two groups, resonant and nonresonant systems according to their working principles. Figure 1 shows the vibration frequency and amplitude for developed vibration systems. Figure 1a shows the highest working frequency and amplitude for non-resonant vibration systems, while Fig. $1 \mathrm{~b}$ shows the fixed working frequency and amplitude for resonant systems. It can be found that the highest vibration frequency of non-resonant vibration system is about $11 \mathrm{kHz}$, but vibration frequency of resonant vibration system is concentrated in $20 \mathrm{kHz}$ and the highest frequency is almost $40 \mathrm{kHz}$. This is due to their different working principles. Generally, better cutting performance and lower tool wear can be obtained when increases vibration frequency in resonant system. For non-resonant vibration system, wider vibration frequency and amplitude bandwidth leads to more complex tool trajectories, expanding their application range.

\subsection{Resonant vibration systems}

As a technology that has been successfully applied commercially, resonant vibration-assisted machining systems work at the natural frequency of the system and apply the excitation vibration principle to increase the amplitude of vibration. A typical design for an ultrasonic vibration-assisted machining system is the resonant rod-type, which consists of three parts; namely, an ultrasonic transducer, acoustic waveguide booster, and horn (see Fig. 2). In some research, the acoustic waveguide booster and horn are also called a sonotrode because the functions of the two components are quite similar [17]. The ultrasonic transducer is the source of vibration for the whole system and converts electrical energy into mechanical motion in longitudinal or compressive mode under self-excited vibration [18]. Two types of electromagnetic and piezoelectric transducers are widely used and were introduced in the previous section. The high-frequency low-amplitude reciprocating harmonic vibration is generated by the ultrasonic transducer and amplified by the sonotrode to the desired location of a tool or workpiece. The sonotrode works by resonating with the transducer and there are strict requirements for its design and
Fig. 1 Vibration frequency and amplitude for developed vibration systems, (a) non-resonant vibration system and (b) resonant vibration system
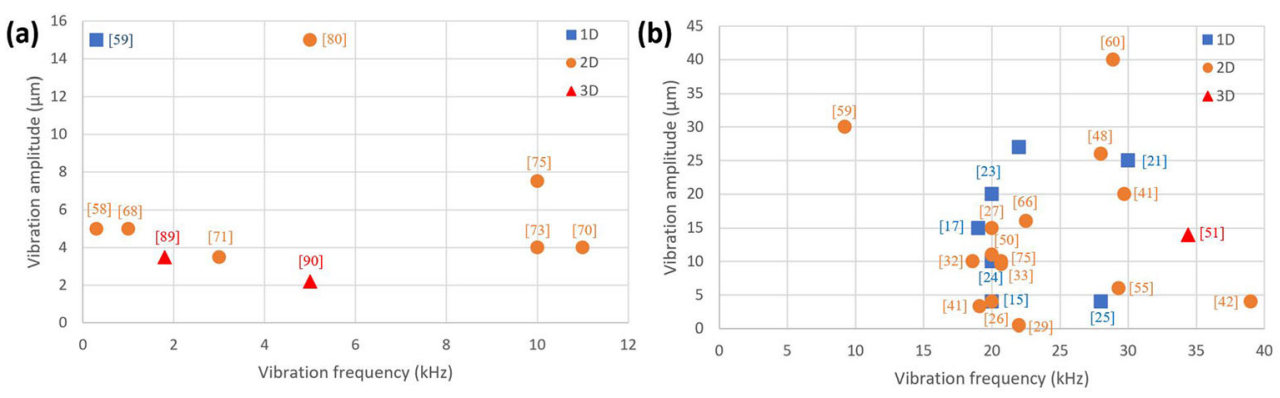

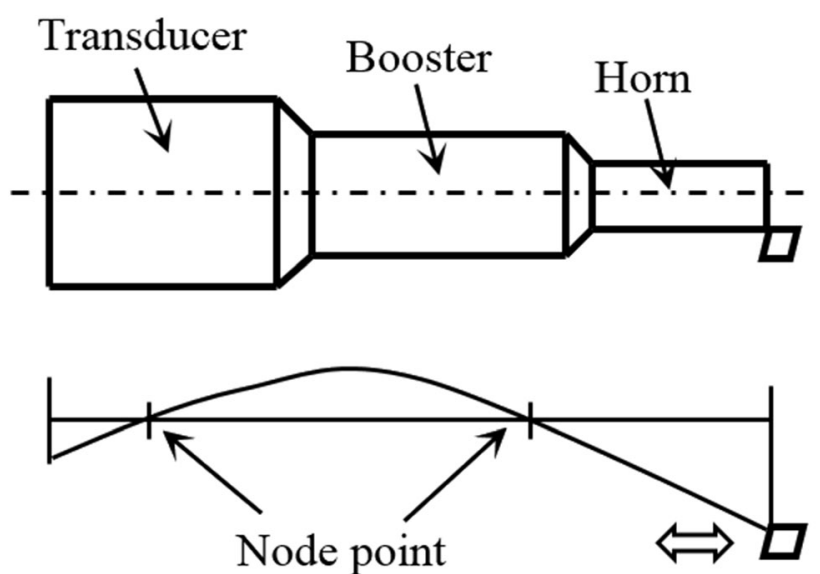

Tool or workpiece vibration

Fig. 2 Typical design of a resonant vibrator

manufacturing. Poor design or fabrication will decrease the energy efficiency, reduce the cutting performance and vibration system durability, and may even cause serious damage to the transducer $[1-3,19]$. The cutting tool or workpiece is attached to the end of the horn to obtain the desired vibration. Moreover, the hold point of the whole system is usually set at node point with zero displacement in order to maintain its stability and reduce energy loss. According to the direction of movement, a resonant vibration system can be divided into three groups: 1D, 2D, and 3D systems.

\subsubsection{D system}

1D ultrasonic vibration-assisted machining systems are the most common type due to their simple structure and ease of implementation. They can be divided into resonant rod and resonant tool types. Many researchers have proposed their own rod-type vibrators. Zhong et al. [4] improved the typical resonant rod-type system and applied it to the turning process, as shown in Fig. 3. A tool holder with a notch structure is introduced into the design to hold the tool firmly in place and to reduce its moving in the other degrees of freedom. During the machining process, bending occurs at the notch point to prevent deformation in the rest of the tool holder. Otherwise, the tool holder in proximity to a parabolic shape will affect machining performance. To obtain a more accurate measurement of cutting force during the vibration-assisted milling process, a special clamp system was designed by Shen et al. [5] by integrating the clamping system and a dynamometer, as shown in Fig. 4. The results showed that the impact of ultrasonic vibrations on measurement results are reduced effectively. Similarly, Liu et al. [6-8] studied ductile mode cutting with tungsten carbide, as shown in Fig. 5. The new clamping system fixes the vibrator using four bolts,

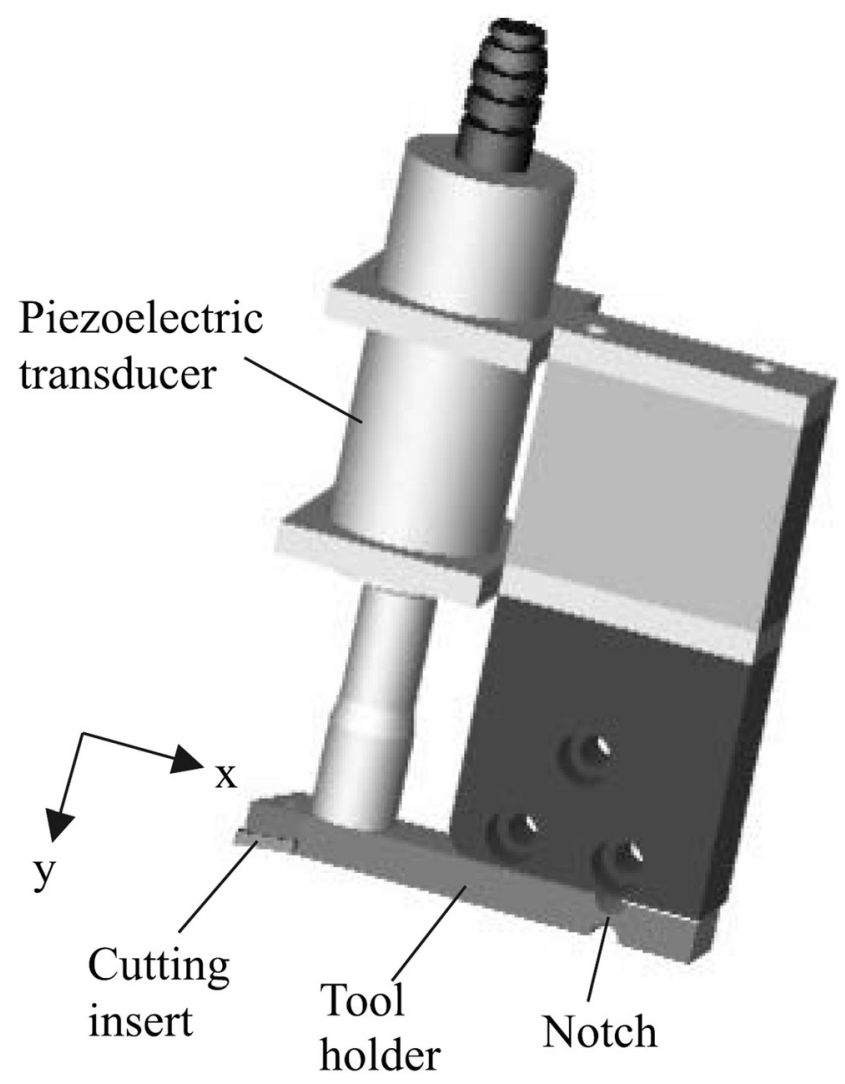

Fig. 3 Vibrator proposed by Zhong et al. [4]

which simplifies the installation procedure of the vibrator and improves its accuracy.

The resonant rod-type 1D resonant vibration system has a simple structure and high reliability; however, the resonance frequency of the system can be easily influenced when a workpiece or large mass is attached to the horn. Meanwhile, the issue of the installation of oversized part is also difficult to solve. Therefore, another type of resonant vibration system named resonant tool was developed by integrating the resources of vibration into the tool holder. A typical design was proposed by Ostasevicius et al. [20], as shown in Fig. 6 . The milling cutter assembly is driven by piezo ceramic rings which are fixed into a standard Weldon tool holder and generate resonant tool movement in the vertical direction. Similarly, Alam et al. [21] improved the tool cutting assembly design and obtained a sevenfold increase in vibration amplitude by using a stepped shape of horn structure (Fig. 7).

As discussed in the previous sections, the vibration parameters for an ultrasonic vibration system largely depend on the dimensions and cross-sectional shape of the designed vibration transmission mechanism consisting of the booster and horn. However, the traditional approach is based on the application of differential equations where the equilibrium of an infinitesimal element is taken into consideration under the influence of elastic and interia forces. This is timeconsuming and inaccurate. To overcome these drawbacks, 


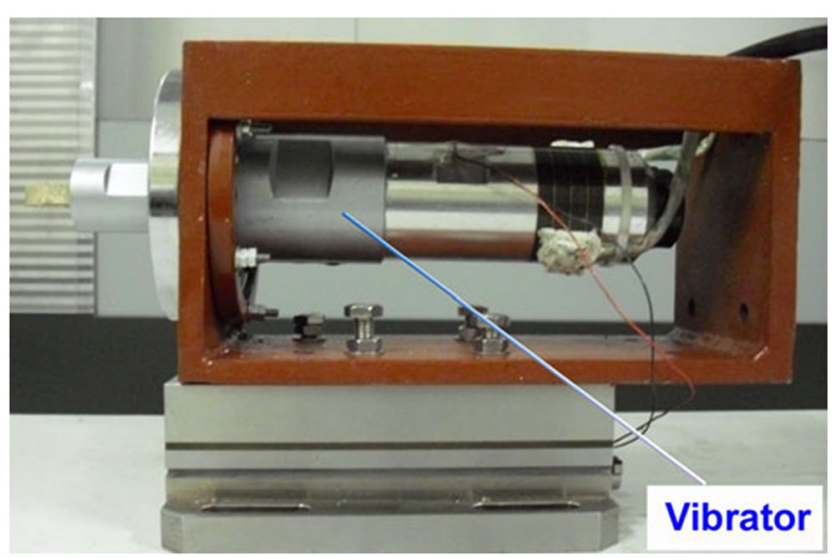

Fig. 4 Vibrator proposed by Shen et al. [5]

FEA is introduced at the design stage of the ultrasonic vibration system, and its use can increase the accuracy of the vibration system, such as in natural frequency and the dimensions of the mechanism, which speeds up the development of vibration devices. Kuo [22] proposed a milling cutter assembly design where the process of harmonic piezoelectric vibrations was simulated by an FEA dynamic simulation which optimized the key dimensions, reduced the influence of stress concentration on the system, and increased its system efficiency. However, the simulation did not consider a situation where a tool is attached to the horn, and this leads to a deviation in the system's natural frequency and vibration amplitude between the simulation results and operational results. Roy et al. [23] developed a circular hollow ultrasonic horn for milling cutter assembly and optimized its outline and crosssectional shape by using FEA. Compared with conventional ultrasonic horn designs, such as those with stepped, conical, and exponential shapes, the circular hollow ultrasonic horn achieved a higher magnification factor and lower axial, radial, and shear stress, hence improving system performance and reducing the influence of stress concentration.

A different type of vibration drilling tool assembly design was proposed by Babitsky et al. [24] (Fig. 8). In order to accomplish vibration-assisted drilling, one side of the

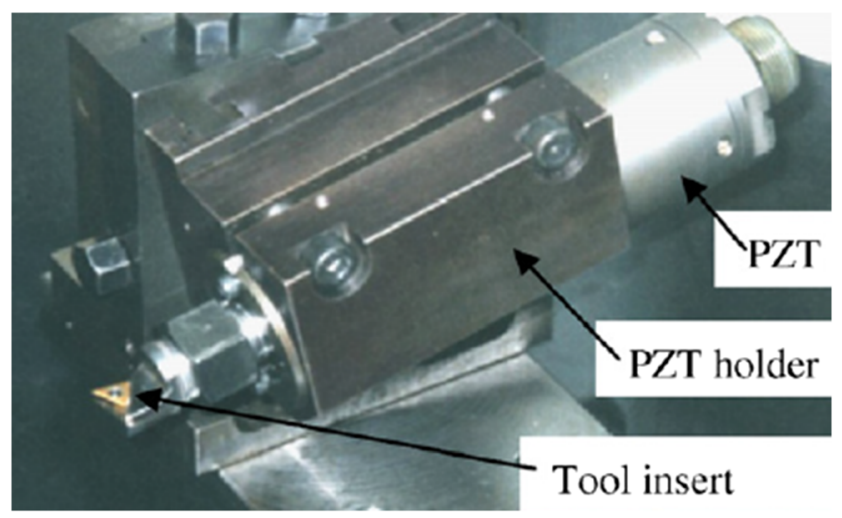

Fig. 5 Vibrator proposed by Liu et al. [6-8] assembly was clamped in the three-jaw chunk of the lathe through the intermediate bush and energized by means of a slip-ring assembly fitted to the hollow shaft of the lathe at the end remote from the chuck. A further 1D ultrasonic vibration system was developed by Hsu et al. [25], and its working principle is quite similar to the ultrasonic bath. As shown in Fig. 9, three commercial Langevin ultrasonic transducers were fixed underneath the vibration stage and were controlled by the same type of signals, generating vibrations at the same frequency and phase. As a result, resonance vibration can be obtained in the vibration stage.

\subsubsection{D and 3D systems}

Ultrasonic elliptical vibration-assisted machining is also named 2D ultrasonic vibration-assisted machining and has received widespread attention since it was first proposed in 1993. Compared 1D systems, 2D systems can obtain better cutting performance and also require a higher standard of vibration devices. Due to its simple structure and ease of implementation, the integrated resonant rod device is the most popular in proposed 2D vibration devices. There are two main designs: patch and sandwich types. For the patch type of integrated resonant rod, two sets of piezoelectric plates are attached to the outer wall of the resonant rod to achieve the same or different modes of resonance. In the sandwich type, two modes of resonance moment can be obtained by adding another set of piezoelectric rings to the 1D resonant rod. Moriwaki et al. [26] developed a 2D patch-type ultrasonic vibration-assisted turning system (Fig. 10) by attaching two pairs of piezoelectric actuators symmetrically in the centre of the four sides of a stepped horn. When two sinusoidal signals with different phases and the same frequency are applied to the piezoelectric actuators, a bending resonance state can be obtained in the vibrator in two mutually perpendicular directions simultaneously and the cutting tool attached at the end of the vibrator vibrates in elliptical mode. The coupling effect cannot be avoided, as the piezoelectric plates are placed in parallel. Shamoto et al. [27, 28] optimized the dimensions and shape of the vibration rod and developed a control system to achieve more accurate tool trajectory. Experiments were conducted on hardened stainless steel and the machining accuracy and machined surface quality improved. A combination of bending and longitudinal vibration modes was also achieved in a different 2D patch-type ultrasonic vibrator designed by Liang et al. [29-31], as shown in Fig. 11. The piezoelectric plates are bonded at the same side of the metal elastic body and the workpiece is fixed to the top of the vibration. However, the vibration amplitudes involved are quite small only up to $0.4 \mu \mathrm{m}$ due to mass issues with the vibrator, and an effect of workpiece mass on the vibration's amplitude and frequency is unavoidable. 
Fig. 6 Vibrator proposed by Ostasevicius et al. [20] (a)

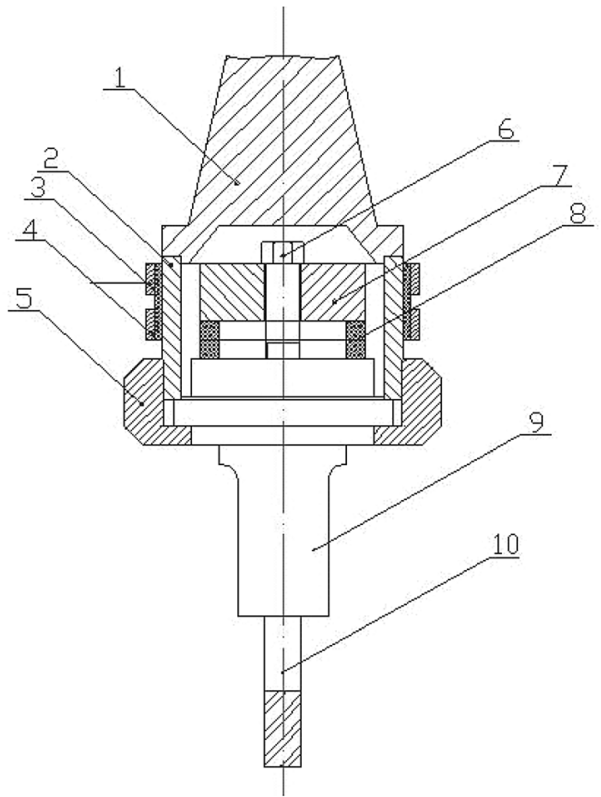

(b)

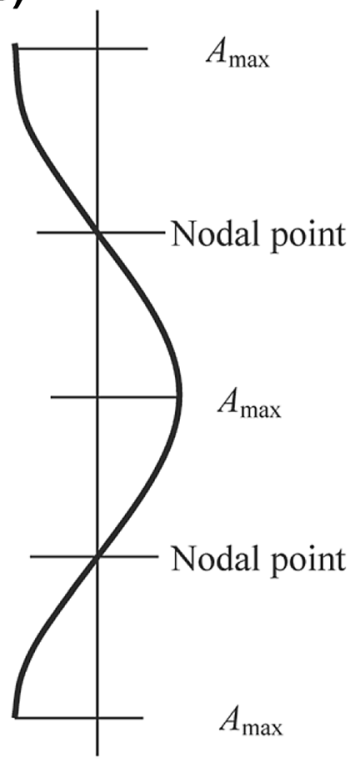

a) Structural diagram of the vibration milling tool; and b) schematics of its operation principle: 1 - standard holder (Weldon) DIN 6359, 2 - cylinder, 3 - textolite cylinder, 4 - collector rings, 5 - nut, 6 - bolt, 7 - collet, 8 - piezoceramic rings, 9 - horn, 10 - cutter

A typical sandwich-type elliptical ultrasonic vibrator is shown in Fig. 12 [32, 33]. The two groups of piezoelectric rings are sandwiched together in the drilling cutter assembly, and each group works at a different resonant mode to generate an elliptical tool tip trajectory. It should be noted that the installation point of this type of vibration device should be set at the coincidence point of the two resonance modes. Meanwhile, vibrators for mounting workpiece or non-

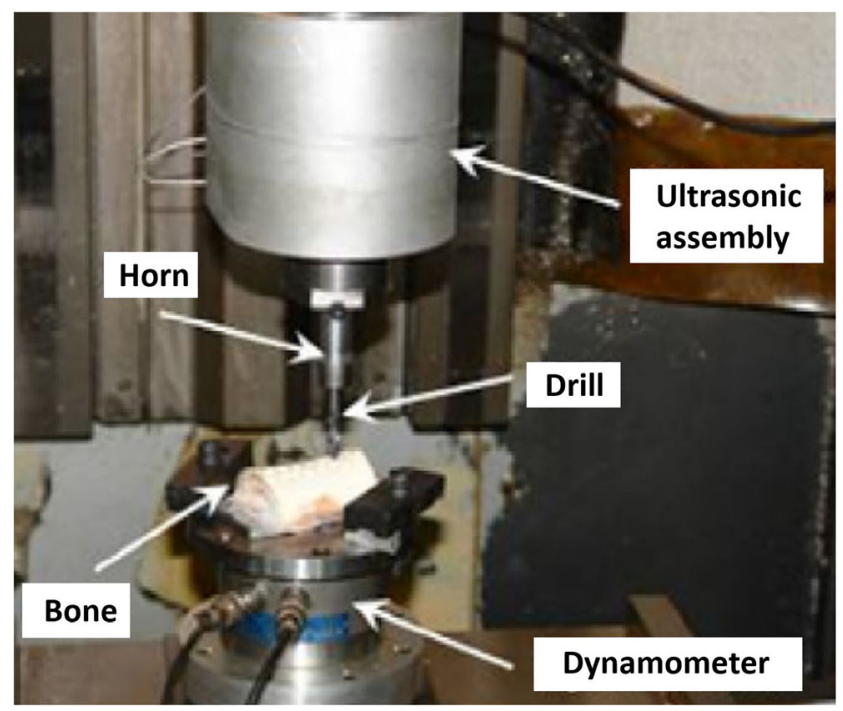

Fig. 7 Vibrator proposed by Alam et al. [21] rotating tools such as for turning and polishing have also been proposed using the same design principle [34-39]. To achieve better performance, Börner et al. [40] developed a crossshaped converter for a 2D ultrasonic vibration-assisted vibrator (Fig. 13) and applied it to the milling process. As the highfrequency vibration is transmitted to the cross-converter, the extension in horizontal direction will lead to a compression in the vertical direction. However, only small specimens can be

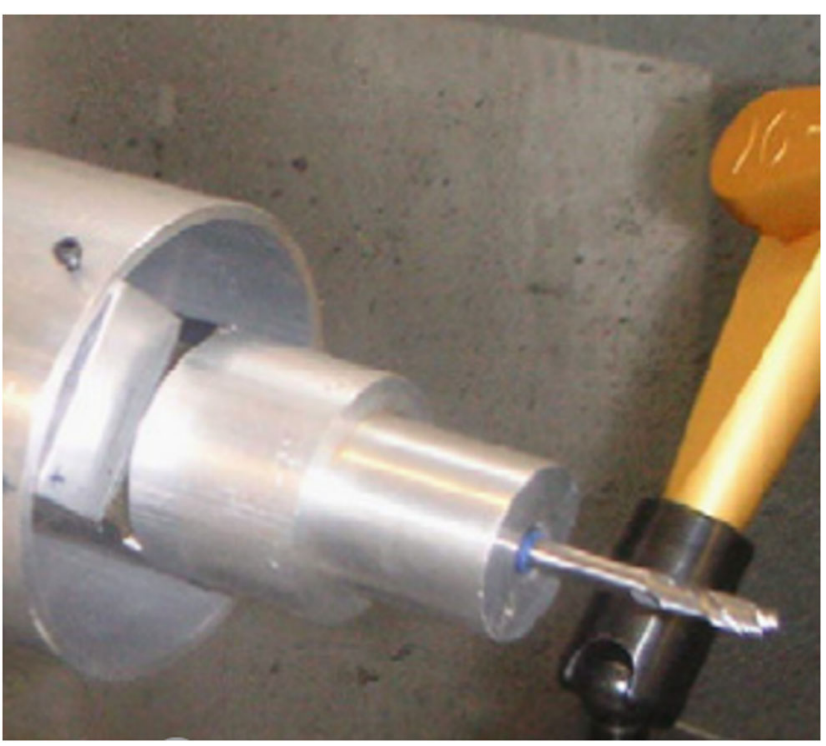

Fig. 8 Vibrator proposed by Babitsky [24] 


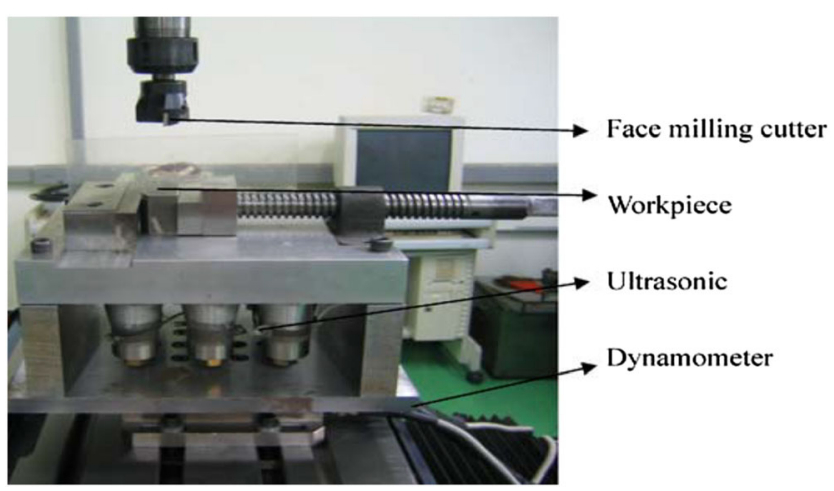

Fig. 9 Vibrator proposed by Hsu et al. [25]

used because those large of mass may influence the resonance frequency of the vibrator. Tan et al. [41] built a symmetrically structured ultrasonic elliptical vibration-assisted device (Fig. 14) using four pairs of piezoelectric rings. The node point of the device is naturally set at the centre of the flange, which is easy to locate. The device is fixed by two pair of grip holes displaced on the both sides of the flange to reduce energy loss and improve cooling performance. Compared with the conventional design, the symmetrical structure can completely balance the internal force, which dramatically reduces error in the vibrator's motion. By changing the piezoelectric actuator to a magnetostrictive actuator, Suzuki et al. [42-44] developed an elliptical vibrating polisher (Fig. 15) and applied successfully it to process micro-aspheric lenses and tungsten carbide die/mould. The vibrator is based on a giant magnetostrictive material and with coils wound around it. It has four legs and each leg can be independently controlled for expansion or contraction. The elliptical tool trajectory can be obtained by appropriately setting the phase

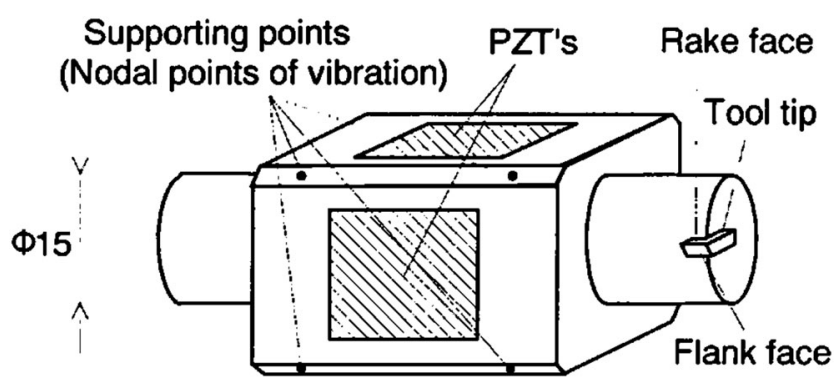

(a) Ultrasonic vibrator

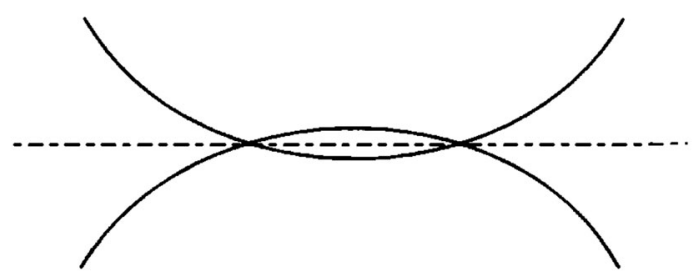

(b) First resonant mode of bending

Fig. 10 Vibrator proposed by Moriwaki et al. [26]

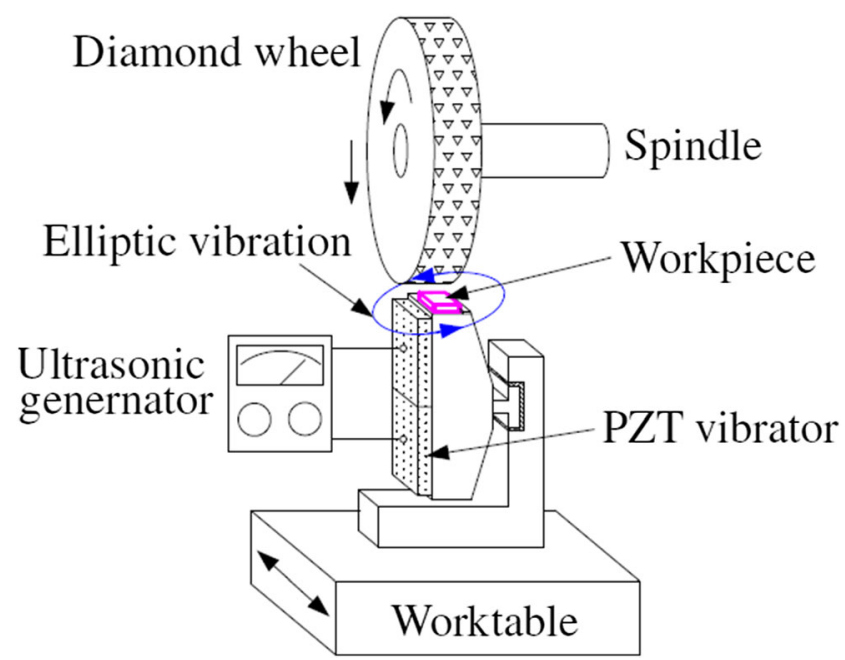

Fig. 11 Vibrator proposed by Liang et al. [29-31]

difference of the two pairs of opposing coils. To obtain the highest vibration amplitude, the vibrator is designed to work at a frequency of $9.2 \mathrm{kHz}$, which limits its processing performance.

Different from integrated resonant mode vibration devices, a separate type of 2D resonant vibrators uses two independent Langevin vibrators placed in a $\mathrm{V}$ or $\mathrm{L}$ shape to obtain a twodimensional vibration of the tool or workpiece [45-47]. Figure 16 shows a typical separate $2 \mathrm{D} \mathrm{V}$-shaped vibrator proposed by Guo et al. [48]. The two Langevin vibrators are set at an angle of $60^{\circ}$ to generate a unique tool tip trajectory. The head block is a flexure structure applied at the end of each vibrator to guide motion and reduce movement error. Each individual vibrator has an added end mass to preload the piezoelectric rings and adjust the natural frequency of the vibrators. A similar design was also applied in a vibration-assisted polishing process [49]. Yan et al. [50] developed a 2D 'L'shaped resonant vibrator for grinding, as shown in Fig. 17. Two independent 1D resonant vibrators are placed perpendicularly on the sides of the vibrating stage. However, this type of 2D resonant vibrator is almost impossible to integrate into a rotating tool such as in a milling cutter assembly, which limits its application.

In order to obtain complex geometrical shapes, the milling process requires a feed vector in arbitrary directions with both vertical and horizontal components of feed vector necessary for $3 \mathrm{D}$ end milling. Hence, there is a need for threedimensional vibration assistance. Figure 18 shows a $3^{\circ}$ of freedom resonant vibration tool which can generate longitudinal and two bending resonance mode vibrations by adding three sets of piezoelectric actuators to a resonance rod [51-53]. The difficulty associated with this design is to accurately locate the node point of the vibration rod and to achieve three modes of resonance frequencies which are as close as possible to obtain sufficient vibration amplitude. Moreover, the cross-talk between the three resonance modes is much 
Fig. 12 Vibrator proposed by Liu et al. [32]

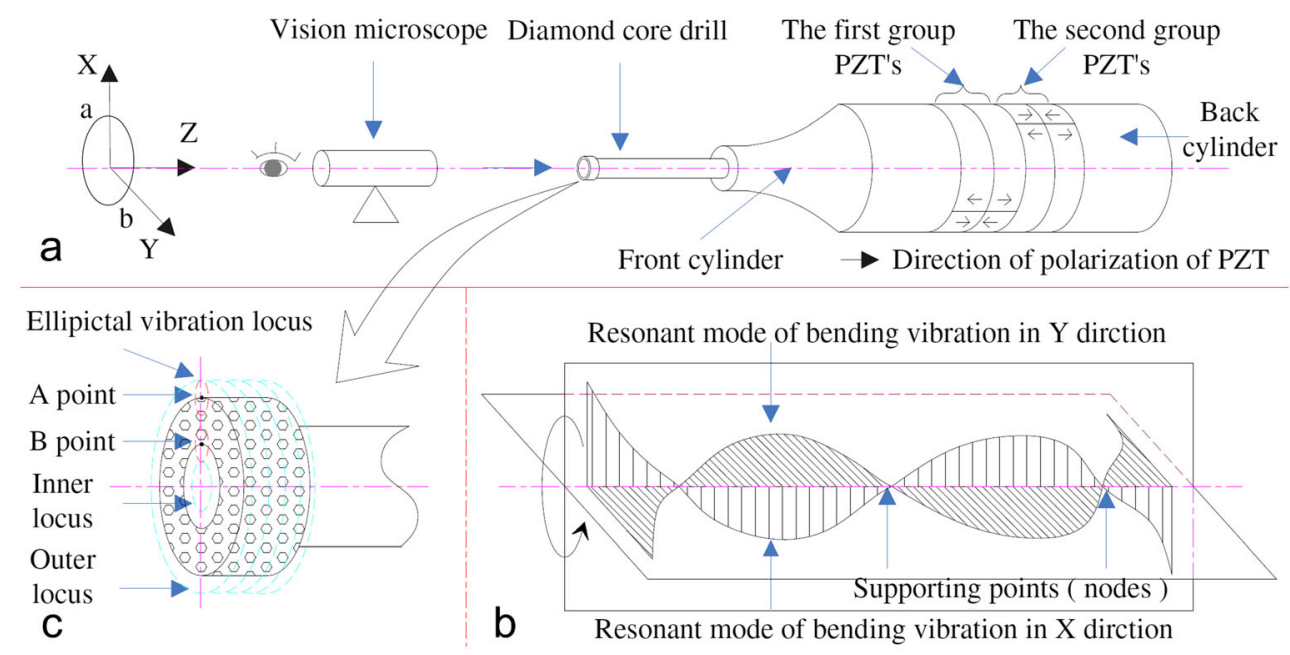

more prominent than that in a $2 \mathrm{D}$ resonant system. In order to reduce the motion coupling effect, stepped and the tapered portions are added to the resonant rod and the overall shape, and dimensions are optimized so as to obtaining optimal performance.

\subsection{Non-resonant vibration system}

Generally, resonant vibration systems are capable of achieving extremely high operating frequencies, and most of them can even reach ultrasonic vibration frequency levels $(\geq$ $20 \mathrm{kHz}$ ). However, their limitations of fixed working frequency and vibration motion parameters, heat dissipation, open loop control, and poor dynamic accuracy are also quite obvious. In addition, the performance of the vibrator heavily relies on the dynamic characteristic of the vibration horn, which increases the difficulty of vibrator design. To overcome these shortcomings in the resonant vibrator, much more attention has been paid to non-resonant vibration systems. Nonresonant systems apply forced vibration rather than excitation vibration as the design principle and produce variable vibration frequencies. However, it is hard to achieve a high working frequency, which is always less than the natural frequency, due to the issue of structural stiffness. Many of these designs

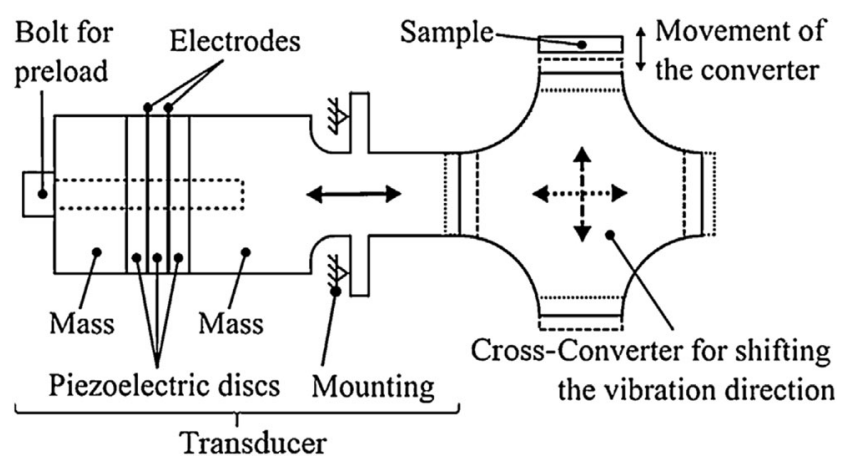

Fig. 13 Vibrator proposed by Börner et al. [40] are inspired by high-precision micro/nano-positioning stages $[54,55]$, and are discussed below.

The working principle of non-resonant vibration system can be explained by the schematic diagram in Fig. 19. The whole system is driven directly by the preloaded piezoelectric actuator. In order to accurately transmit motion and reduce parasitic movement, flexible mechanisms (flexure hinges), which can be simplified into a set of spring-damper mechanisms, as shown in Fig. 19, are always chosen as the linkage between the actuators and end executor. A displacement amplifying mechanism can be integrated into the flexure hinges if the amplitude is required larger than the displacement generated by the piezoelectric actuator. Moreover, decoupling issues also need to be considered in the design phase of the flexible mechanism when multidimensional motions are required.

Compared with resonant vibration systems, higher motion accuracy can usually be achieved with a non-resonant vibration system due to its inherent merits. This makes it more suitable for the manufacturing of micro-structured surfaces. Therefore, 1D non-resonant vibration systems are quite rare due to the complex tool trajectories required in producing unique surface microstructures. A typical design of a 1D non-resonant vibration system uses a combination of a parallel four-bar flexure hinge structure and a piezoelectric actuator [56]. Figure 20 shows a 1D non-resonant vibration system design proposed by Long et al. [57, 58]. A single piezoelectric actuator is positioned at the parallel four-bar flexure hinge structure, which also includes a vibration displacement amplification function. The structural layout and closed-loop control system ensure high motion precision. A different design was proposed by Suzuki et al. [59] with a complex mechanical structure, as shown in Fig. 21. To ensure cutting accuracy, this vibrator aims to achieve high axial mechanical stiffness so as to reduce elastic deflection during the machining process. A cylindrical roller bearing is set between the cutting tool and piezoelectric actuators to guide the vibration and support the 
Fig. 14 Vibrator proposed by Tan et al. [41] (a) Round nut Bending PZT ceramics Longitudinal PZT ceramics Vertical direction

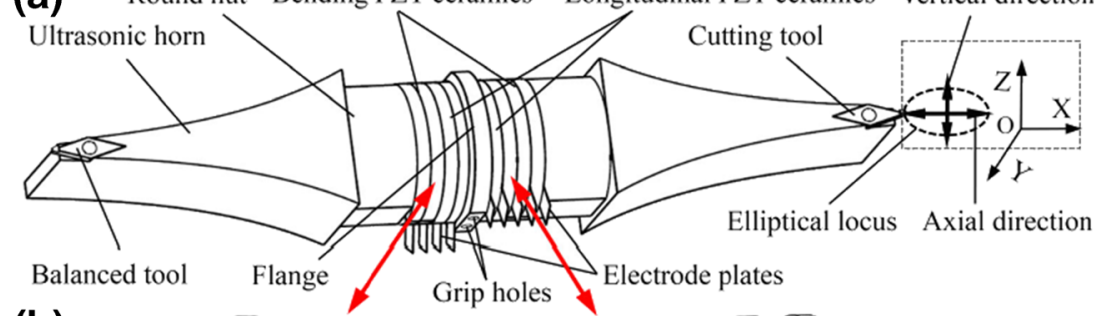

(b)
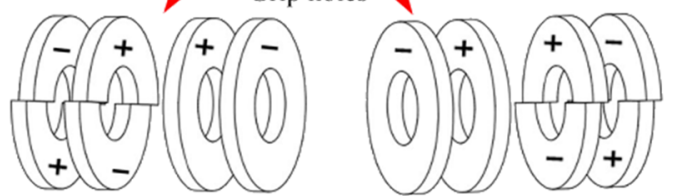

(c)

6 th resonant mode of bending vibration 3rd resonant mode of longitudinal vibration

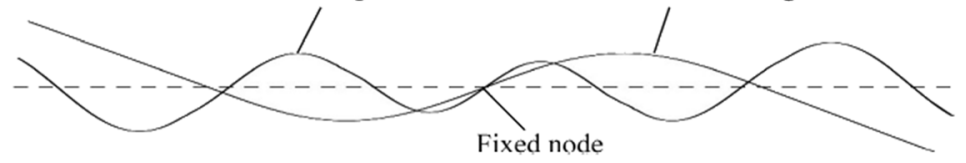

bending force acting on the cutter insert, and the twisting force in the machining process is supported by the pin. Moreover, bending stress is further reduced due to the flexible tip. Consequently, the shear stress which could damage them cannot be transmitted to the piezoelectric actuators. Because the output voltage for the control of the vibrator may reach up to $1000 \mathrm{~V}$, an air-cooling system is also integrated into the vibrator to prevent overheating.

\subsubsection{D system}

Compared with 1D systems, the application of 2D systems is more flexible. However, the coupling effect between the two vibration directions has a great impact on its accuracy. Two configurations exist among the proposed designs, a vibration tool mainly for turning, and a vibration stage mainly for milling. A flexible hinge structure is often used to guide motion, and to reduce motion error and the coupling effect, although some other designs have also been reported. Brehl et al. [60, 61] developed two types of non-resonant elliptical vibration-assisted machining devices at two different working frequencies. One of these vibrators (Fig. 22a) works at a high vibration frequency up to $4.5 \mathrm{kHz}$ but low vibration amplitude of less than $2 \mu \mathrm{m}$ and requires a cooling chamber to prevent the vibrator from overheating. The other design (Fig. 22b) operates at a low vibration frequency of $400 \mathrm{~Hz}$ but high vibration amplitude up to $22 \mu \mathrm{m}$ and does not need an extra cooling system. The design principles of the two vibrators are almost the same. Two piezoelectric actuators are placed in parallel and generate two sinusoidal vibrations with a specific phase difference. Then, two sets of parallel high-frequency vibration motions are converted by the ' $\mathrm{T}$ ' shape tool holder

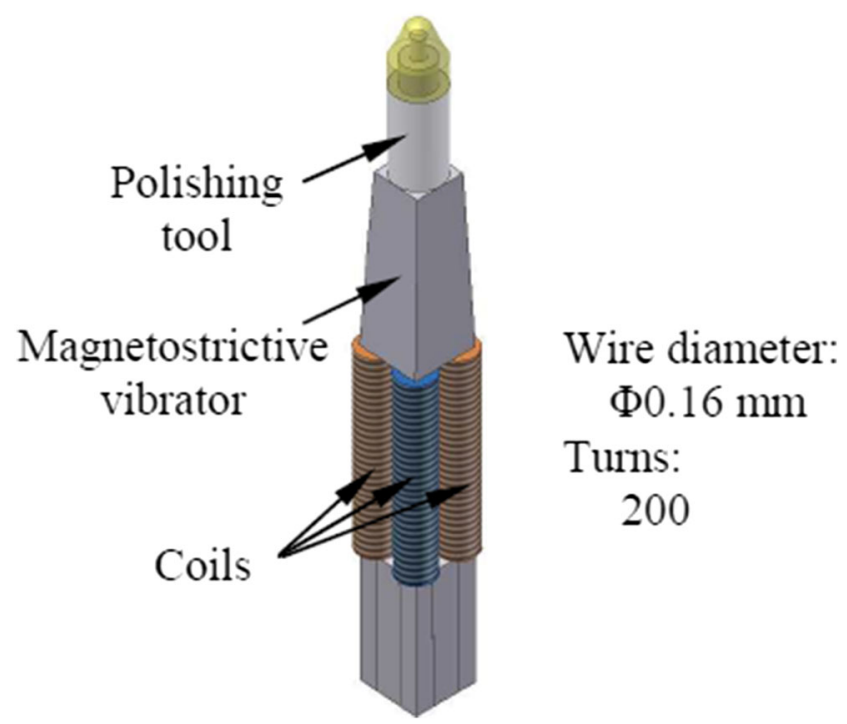

Fig. 15 Vibrator proposed by Suzuki et al. [42-44]

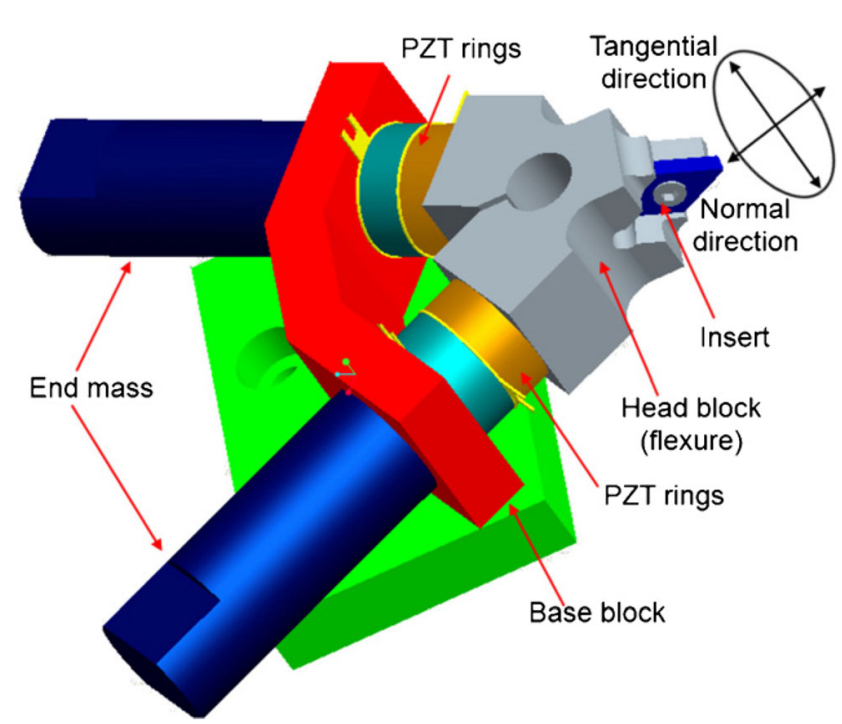

Fig. 16 Vibrator proposed by Guo et al. [48] 


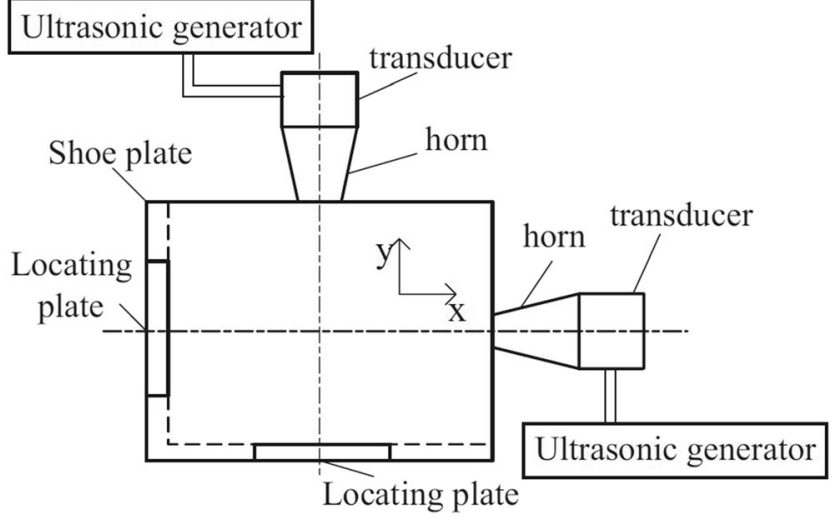

Fig. 17 Vibrator proposed Yan et al. [50]

into the desired elliptical cutting tool trajectory. To simplify the structure and improve the working frequency band of the vibrators, the piezoelectric actuators are used to achieve cutting tool support and positioning in both vibrator designs. However, the drawback of this design is that the accuracy of the vibrators is hard to guarantee under the conditions of open loop control. Therefore, it is not suitable for the precision machining processes due to the non-linear hysteresis and creep behaviour of the piezoelectric actuators which is unavoidable.

Another two design of 2D non-resonant vibration tool assembly (Fig. 23a and b) were proposed by Kim et al. [63-65]. Two stacked piezoelectric actuators are fixed/preloaded by a through-bolt on the tool holder and placed in parallel and perpendicular to each other, respectively. A similar design proposed by Li et al. [66] uses four pairs of piezoelectric plates symmetrically placed at both side of the vibration platform. However, the major drawback of these designs is the motion coupling between the two motion directions, which causes tangential shear stress inside the piezoelectric actuator and damages the vibrator. To overcome these drawbacks, many optimized design proposals have been proposed. Loh et al. [67] improved the current vibrator design and a better performance was obtained in their experiment results (see Fig. 24). Compared with the original design, the structure of the tool holder is optimized and a hemispherical structure is added at the junction of the piezoelectric actuator and tool holder, which changes the connection mode between them from surface contact to point contact. As a result, the motion coupling

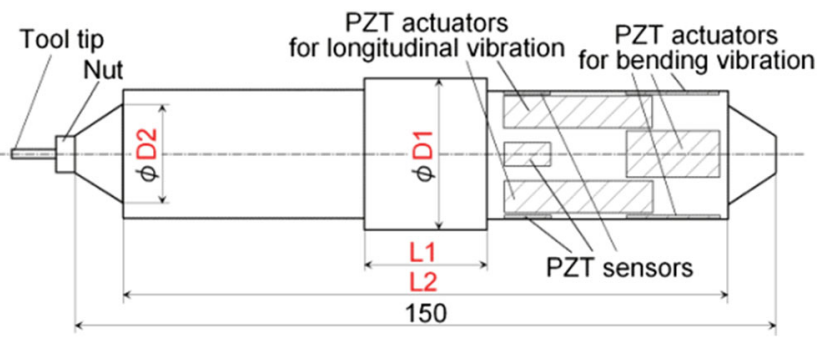

Fig. 18 Layout of the 3D vibrator [51-53]

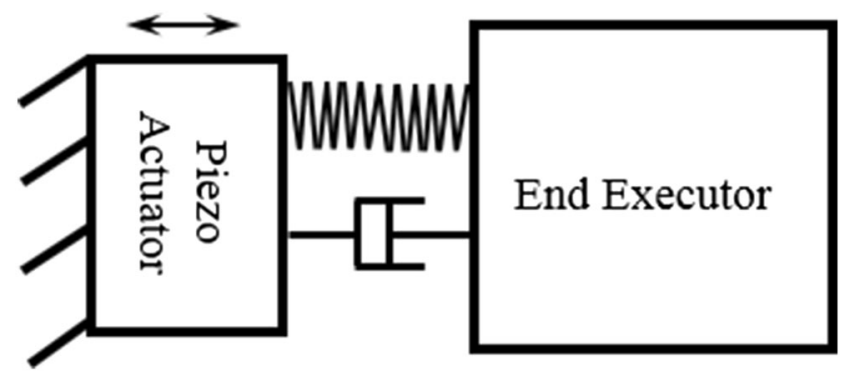

Fig. 19 Typical working diagram of non-resonant vibrator

between the two piezoelectric actuators can be effectively avoided and potentially hazardous shear deformation of the piezoelectric actuators reduced. Another design adds crossshaped voids to the tool vibrator, and the results show that the cross-interference of the vibration of each axis is effectively suppressed [68]. Chern et al. [69] put forward a different vibration design employing a combination of piezoelectric actuators and linear guideways (see Fig. 25). However, the coupling effect cannot be reduced effectively because the end spring of the vibrating stage has no torsional stiffness.

To obtain better cutting performance and a more accurate tool tip trajectory, various non-resonant vibration stages with flexible structures have been proposed. One of these designs uses independent driving, where each group of piezoelectric actuator drives one direction of the vibrator and movement in each direction is independent of the others in order to minimize mutual coupling. A typical 2D non-resonant vibration stage based on the flexible structure was developed by Jin et al. [70]. The movable vibration table is connected to the piezoelectric actuators through flexible hinge structures in both directions. As the two piezoelectric actuators work together, the motion of the flexure hinges will be affected by coupling stiffness leading to an uneven displacement between the two directions, which makes it hard to control them precisely. Ding et al. [71, 72] built a non-resonant elliptical vibration stage using a parallel-kinematic double flexible hinges structure. The stage is driven by two independent piezoelectric actuators which are placed perpendicular to each other. The parallel-kinematic double flexible hinge structure has advantages such as compactness, high stiffness levels, and no friction. In addition, it also reduces the coupling effect of the vibration stage. A single flexure parallel four-bar elliptical vibration stage has been developed using four flexible hinges supporting the movable stage (see Fig. 26) [73]. However, when the vibration stage vibrates in one direction, parasitic movements in the other direction (perpendicular direction) cannot be eliminated due to the coupling effect of the single parallel four-bar mechanism. A planar-integrated vibration stage with a symmetrical double flexible parallel four-bar structure was proposed by Zhang et al. [74]. It features a compact structure, zero clearance, and no mechanical friction, which leads to better guidance properties. Compared with the 


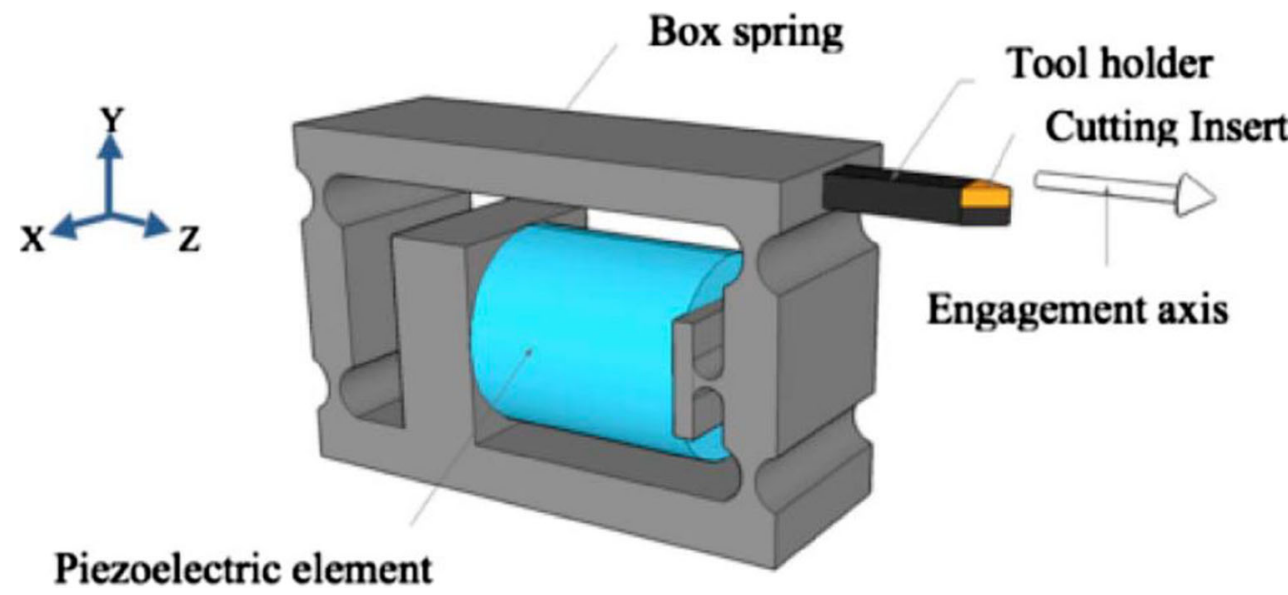

Fig. 20 Vibrator proposed by Greco et al. [57]

single-parallel four-bar structure vibration stage, it not only eliminates the cross-coupling displacement, but also weakens the external interference to a certain extent. By optimizing existing designs, Chen et al. [75-79] reported a 2D highly dynamic horizontal non-resonant vibration-assisted milling system. As shown in Fig. 27, a structure of double parallel four-bar linkages with double-layer flexible hinges is applied to the vibration stage design, which not only reduces the coupling effect, but also improves efficiency of the vibration transmission. The stiffness and displacement of the vibrating

Fig. 21 Vibrator proposed by Suzuki et al. [59]

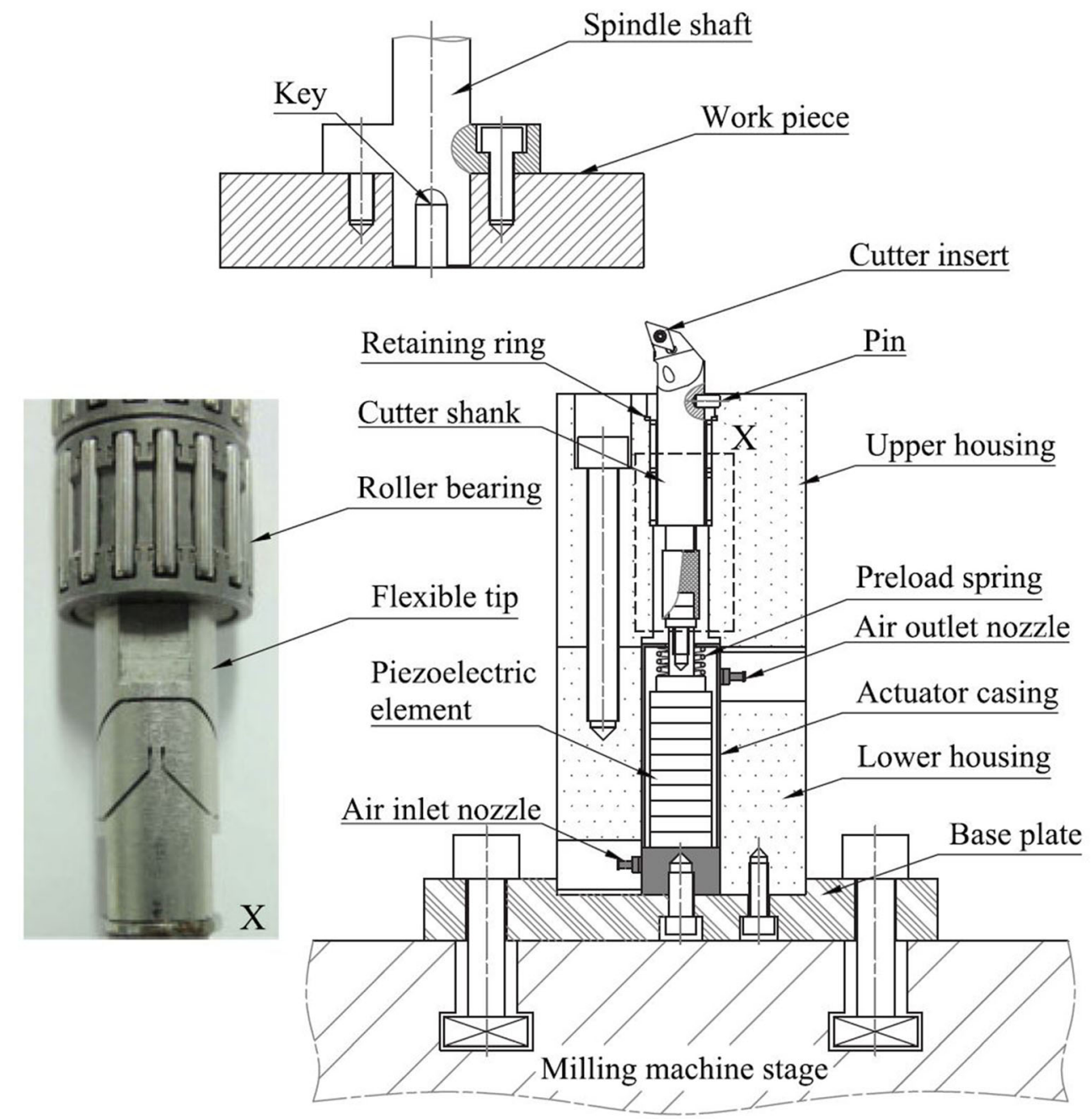


Fig. 22 Vibrator proposed by Brehl et al. [61, 62] (a) Cooling chamber

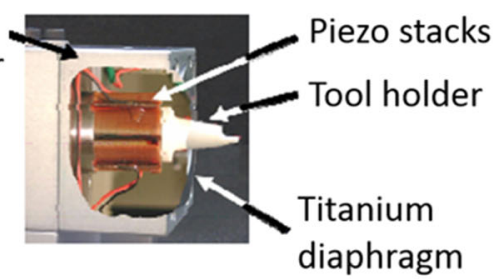

(b)

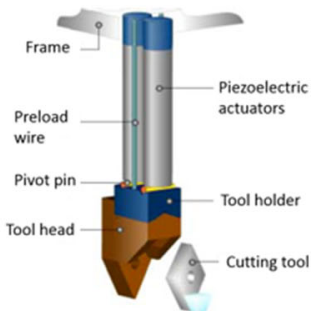

stage are assured by adjusting the dimensions of the different flexible hinges. Another compact 2D non-resonant vibration stage design was proposed [80, 81]. Two pairs of piezoelectric actuators are placed symmetrical in flexible hinges around the oval mechanical structure. The circuit board is integrated into the vibration stage, which reduces the device's volume.

Another design applies two or more piezoelectric actuators in the same or multiple directions to produce a compound elliptical motion. A more complex tool trajectory can be obtained compared with an independently driven vibrating stage. In order to reduce the influence of other factors on the vibration amplitude and frequency, it is usually integrated with the machine tool [82]. A flexible hinge structure-based 2D vibration turning tool was also proposed as shown in Fig. 28 [83]. The design principle of the vibrator uses a set of vertically connected biaxial flexible hinges to support and guide the tool holder. When the tool holder is driven by two piezoelectric actuators, the elastic deformation of the flexible hinges in different directions can be employed to synthesize the motion of elliptical tool tip. Lin et al. [84] reported a piezoelectric tool actuator (PETA) for elliptical vibration turning based on a hybrid flexure hinge connection (see Fig. 29). It consists two parallel four-bar linkage mechanisms and two right circular flexure hinges and effectively improves vibration accuracy and reduces the coupling effect between the two motion axes. The step responses, motion strokes, vibration resolutions, parasitic motions, and natural frequencies of the PETA along the two input directions were analysed, and the results show that the vibrator is capable of precision machining. A 2D-proposed low-frequency vibration-assisted polishing tool assembly is shown in Fig. 30 [85]. It consists of four mechanical amplitude-magnified actuators screwed together on a centre piece which generates a planetary elliptical tool tip trajectory. Although the non-integral structure reduces the design and manufacturing difficulty of the vibrator, higher installation accuracy is also required due to the fact that the assembly accuracy has a great influence on the vibrator motion trajectory. To solve this problem and achieve higher tool motion accuracy, another 2D low-frequency vibrator is shown in Fig. 31 [86]. Three mechanical amplitude magnified actuators are arranged in a triangle around the centrepiece, and a highly repeatable and stable polishing trajectory can be obtained. In addition, the 2D low-frequency vibrator is attached to a low contact force loader, which further reduces the polishing force and prevents damage to the surface layer of the workpiece. Compared with the previous system, this vibration system has advantages such as higher vibration accuracy, and lower grinding force and energy consumption, and the resolution of the vibration is also improved to $0.1 \mu \mathrm{m}$.

\subsubsection{D systems}

As an important part of non-resonant systems, the 3D vibration system can generate a more complex tool trajectory which is suitable for special applications such as the production of optical freeform surfaces on hard and brittle materials [87]. Similar to the design of the 2D non-resonant vibrator, the $3 \mathrm{D}$ non-resonant vibrator can also be divided into compound motion and independent drive types. For the latter 3D nonresonant vibrator, the coupling can seriously influence the accuracy of motion due to the motion of the vibration device which is composed of individual movements in three axes. In
Fig. 23 Vibrators proposed by KIM et al. [63-65]
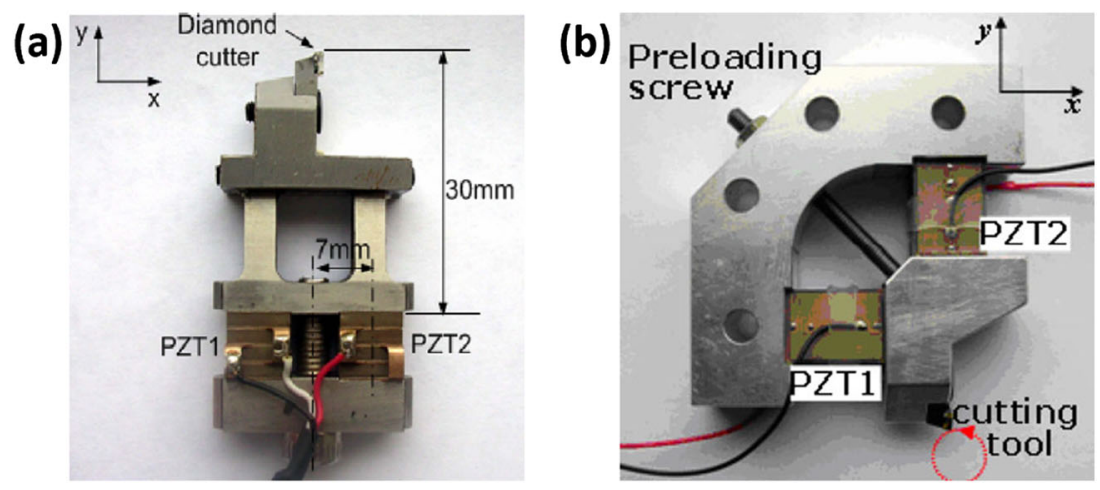


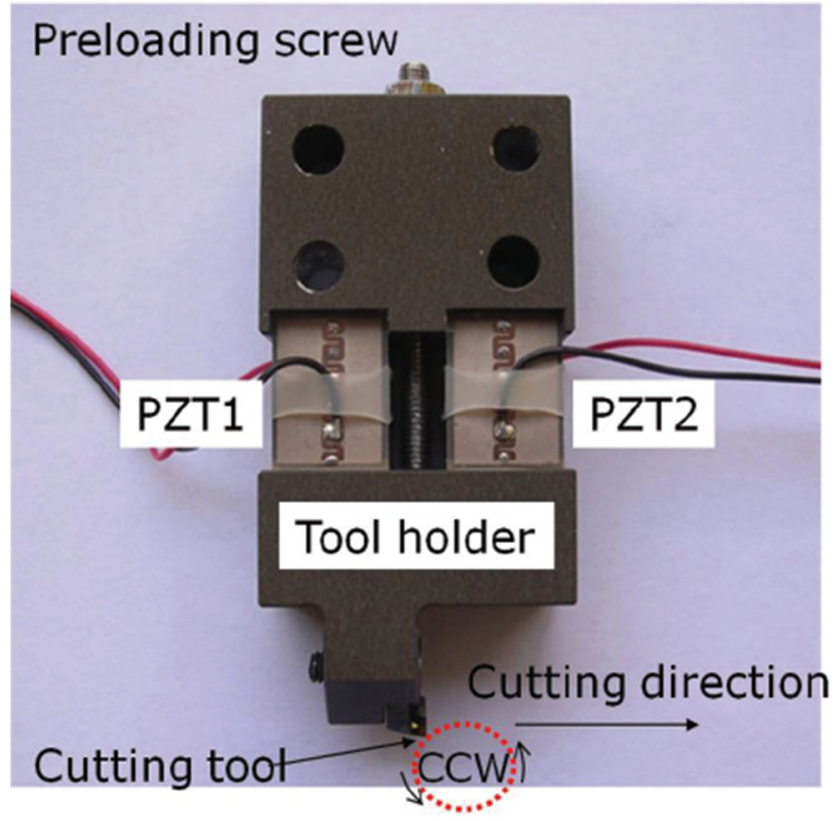

Fig. 24 Vibrator proposed by Loh et al. [67]

addition, the totally decoupled motions always require a large number of linkages with special structures needed for motion isolation, causing relatively low response rates [88]. Wang et al. and Liu et al. proposed two similar 3D non-resonant vibration devices [89, 90]. However, their complex flexible structures result in low bandwidth and response speeds. To overcome these drawbacks, a different type of independent drive 3D non-resonant vibration device has been developed which is shown in Fig. 32 [91]. In this design, low coupling and high motion accuracy and response rates can be obtained by employing a compact and rotationally symmetrical structure and special flexure hinges with multiple DoFs. Figure 33 shows a representative design of the compound motion type $3 \mathrm{D}$ of non-resonant vibration device $[92,93]$. The vibration device is driven by four piezoelectric actuators and the different 3D motion planes and trajectory can be obtained by changing the acting locations of the piezoelectric stacks or parameters of the signals. By installing displacement sensors, this vibration device achieves closed-loop control and better motion accuracy.

\section{Applications and benefits of vibration-assisted machining}

\subsection{Ductile mode cutting of brittle materials}

When the cutting depth is less than a certain critical value (the critical cutting depth) in the processing of brittle materials, the cutting process will be transformed from brittle cutting mode into ductile cutting mode. This removes the workpiece materials by plastic flow instead of brittle fractures, leading to a crack-free surface. In ductile cutting mode, the critical cutting depth can be defined as the cutting depth at which a crack appears on the machined surface. If the undeformed chip thickness is less than the critical cutting depth, brittle cutting can be reduced in conventional cutting and a better surface finish can be obtained. However, in the actual processing of brittle materials, their critical cutting depth is usually in the range of microns or sub-micron, which reduces processing efficiency and increases the manufacturing time. Vibrationassisted machining is an effective method used to increase the critical cutting depth the in ductile cutting mode and to improve the economics and feasibility of the processing of brittle materials. It has been reported that smaller cutting forces can reduce microcrack propagation on the surface of the brittle parts and can increase the critical cutting depth for brittle materials under ductile cutting mode. In addition, a large enough plastic-yielding force, but not large enough to cause material rupturing is also a necessary condition for the ductile cutting of brittle workpieces. Therefore, it is feasible to increase the brittle materials' critical cutting depth within a reasonable stress range by using vibration-assisted machining [94-96].

\subsection{Machining accuracy and surface quality improvement}

Compared with the conventional machining process, vibration-assisted machining can greatly improve machining accuracy and surface quality, and the improvements vary depending on the tool and workpiece materials, vibration conditions (vibration amplitude, vibration

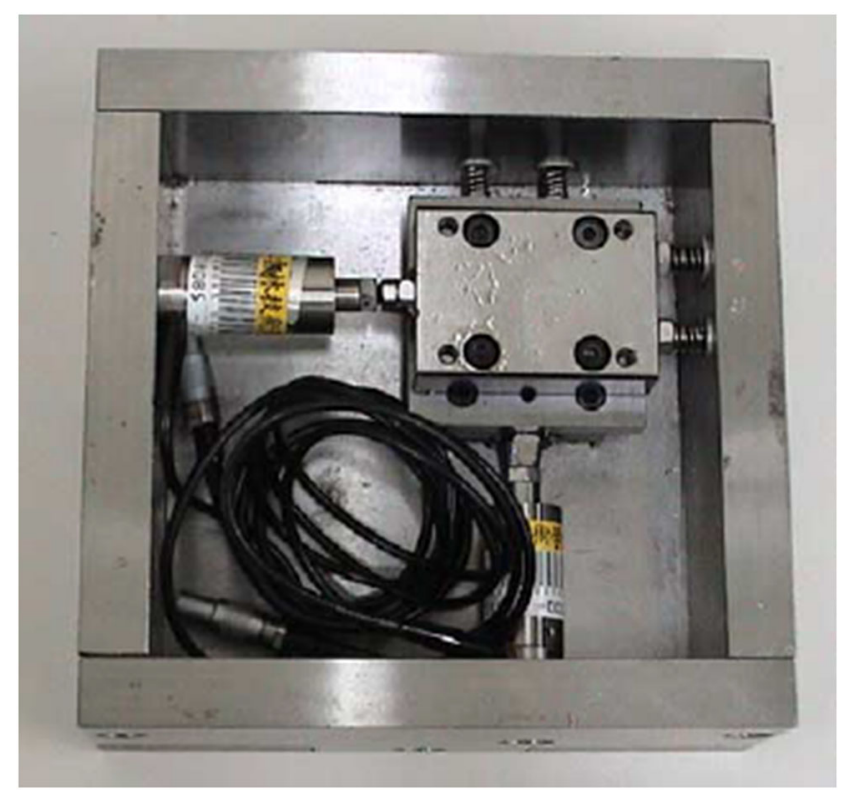

Fig. 25 Vibrator proposed by Chern et al. [69] 


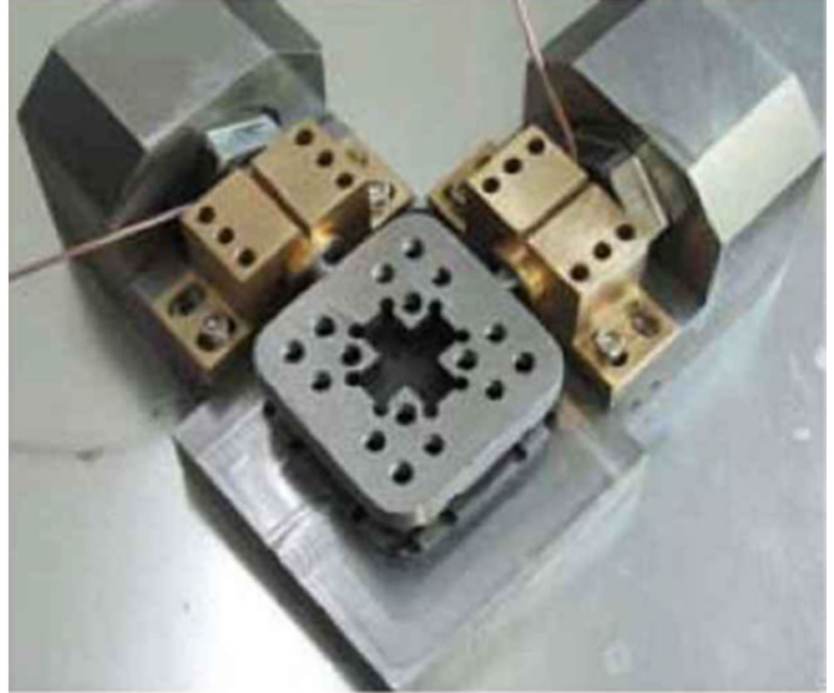

Fig. 26 Vibrator proposed by Li et al. [73]

frequency, and vibration dimensions), tool parameters, and processing parameters such as feed rate, spindle speed, and cutting depth. If the processing parameters are unchanged, the surface roughness in $1 \mathrm{D}$ and $2 \mathrm{D}$ vibration-assisted machining can be reduced by approximately $40 \%$ and $85 \%$, respectively [17]. There are many reasons for this. On the one hand, lower cutting forces can enhance the stability of the cutting process, which reduces tool run-out in the cutting depth direction and generates smaller chips. On the other hand, vibration-assisted machining can reduce cutting tool wear and effectively avoid damage caused to the machined surface by worn tools. The tool's self-excited vibration is replaced with regular

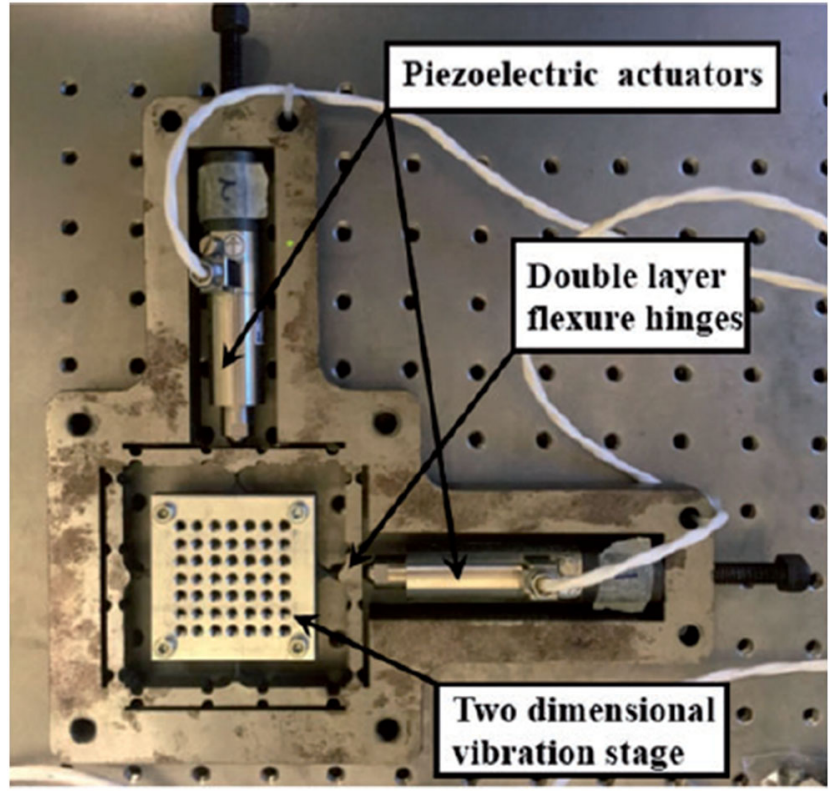

Fig. 27 Vibrator proposed by Chen et al. [75-77]

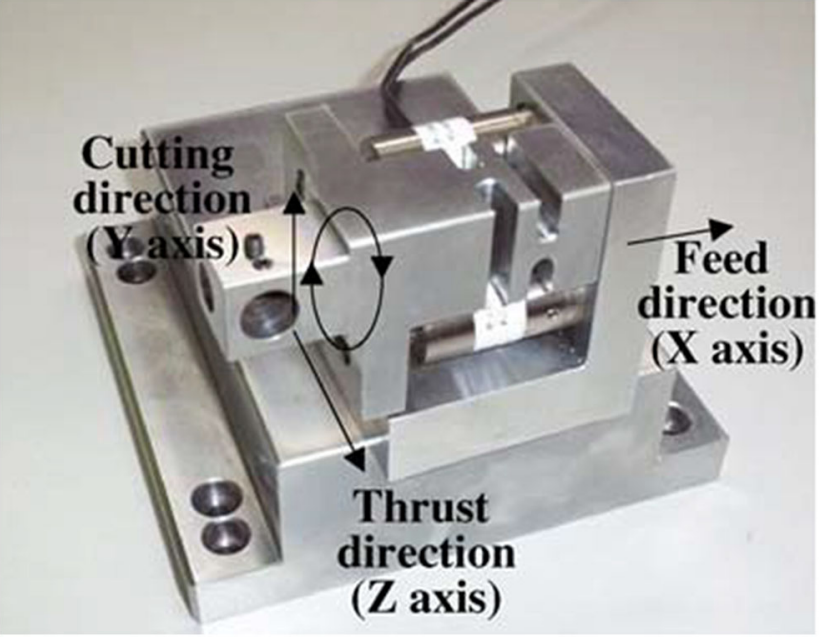

Fig. 28 Vibrator proposed by Kim et al. [83]

sine or cos vibration, which reduces the residual height of the unremoved material. As a result, a better machined surface quality can be obtained.

\subsection{Burrs suppression}

Burr formation, similar to chip generation, is a common and undesirable phenomenon in the machining process and one of the most important criteria in the evaluation of the machined surface. Vibration-assisted machining can effectively suppress burr formation during processing, and some researchers have proposed that burr height can be reduced up to $80 \%$ compared with conventional machining [97-99]. Figure 34 shows examples of burr reduction in vibration-assisted machining. Almost no burrs can be found on the machined surface. This phenomenon is mainly due to the reduced cutting force, which leads to lower transient compressive stress and yield stress in the cutting deformation area. In addition, unique tool

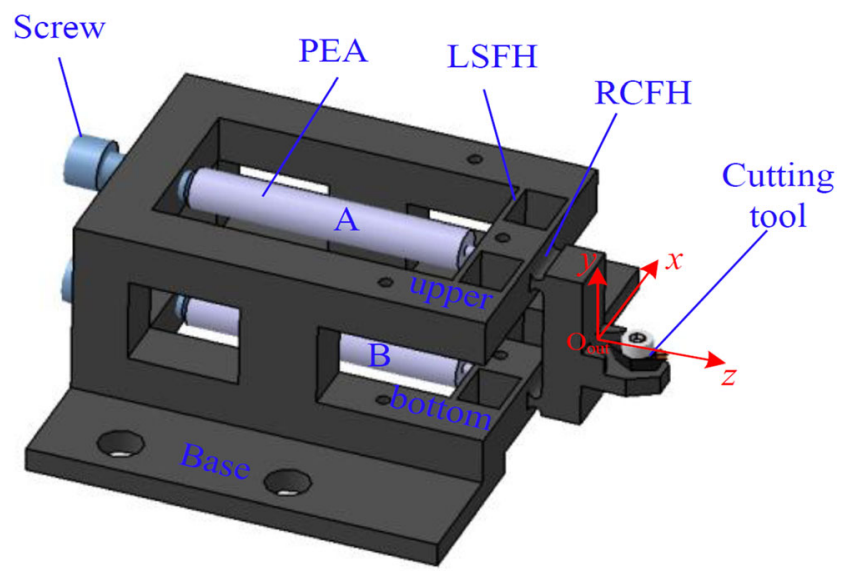

Fig. 29 Vibrator proposed by Lin et al. [84] 


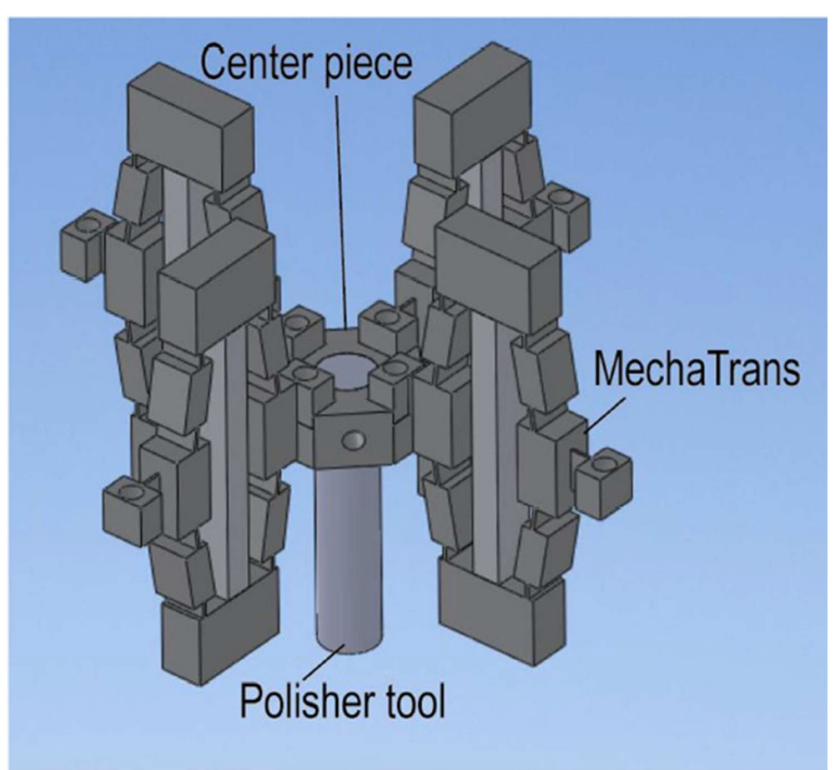

Fig. 30 Vibrator proposed by Chee et al. [85]

trajectories (such as elliptical trajectories) can result in discrete small of pieces chips. As a result, burr formation can be suppressed.

\subsection{Surface texture generation}

Engineered textured surfaces have the characteristics of regular textural structures and high aspect ratio, enabling the component surface to serve specific functions such as reducing adhesion friction, improving lubricity, increasing wear resistance, changing hydrophilic performance, and enhancing optical properties. Etching methods are commonly used to produce high precision surface microstructures, but these are costly and time-consuming. As a more flexible method, it

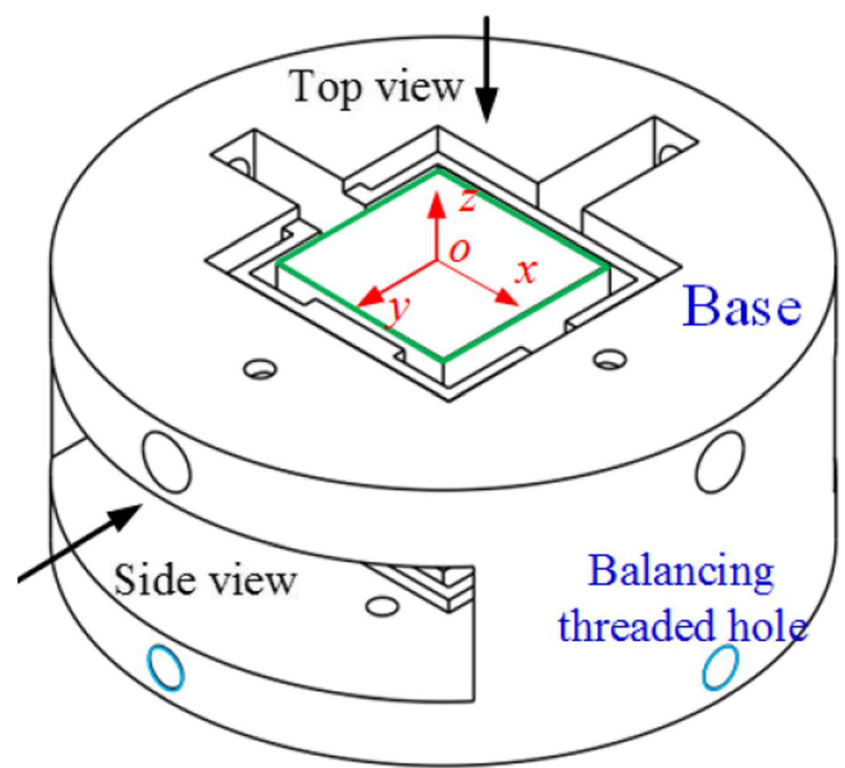

Fig. 32 Layout of a 3D non-resonant vibrator [91]

has been proven that vibration-assisted machining in either a single direction or two directions can form certain surface textures depending on the cutting-edge geometry and kinematics. Currently, the proposed surface textures mainly include squamous, micro-dimple pattern, and micro-convex pattern types, and their size ranges from a few microns to tens of microns, as shown in Fig. 35. There is an emerging trend to obtain certain surface performance using vibration-assisted machining. For example, the size of the surface texture features can be controlled by changing the vibration and processing parameters, leading to variable surface wettability (Fig. 35) [75]. And this process can also be used to create microchannels for the microfluidic control of the fluid flow, to name a few.
Fig. 31 Vibrator proposed by Chee et al. [86]

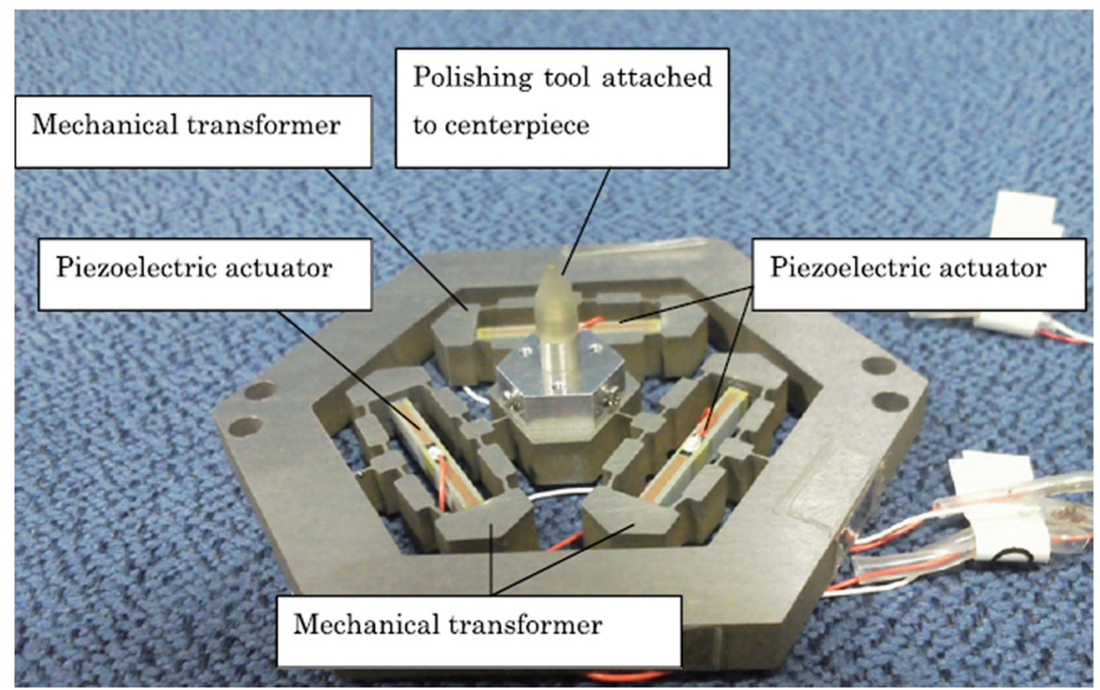


Fig. 33 Compound motion type $3 \mathrm{D}$ vibrator $[92,93]$

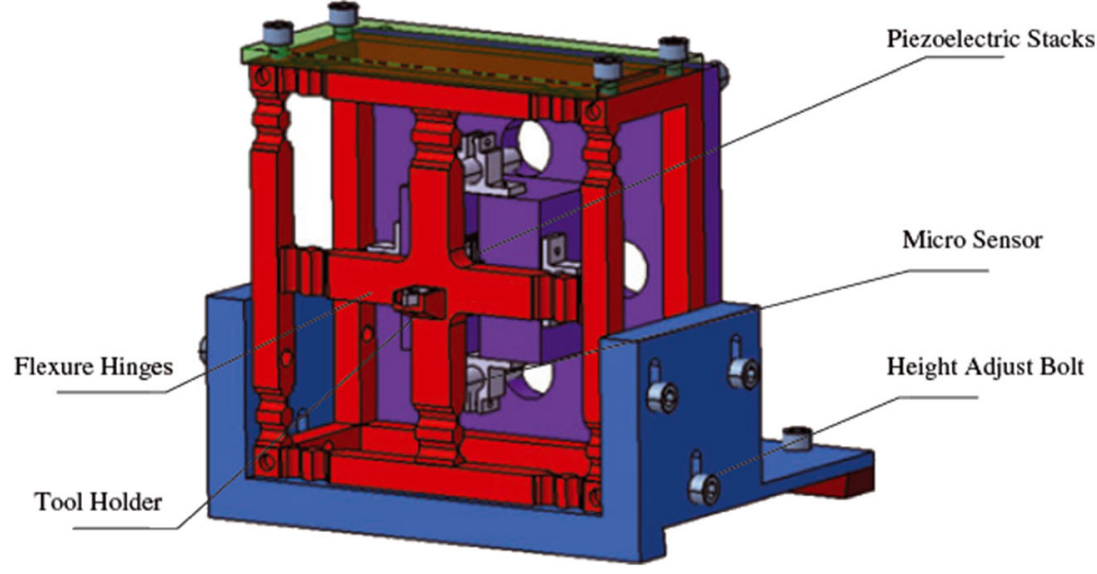

\section{Future perspectives}

With a deeper understanding of the cutting mechanisms in vibration-assisted machining technology, its potential for processing hard and brittle material is gradually being explored. However, this also leads to stricter requirements for stability and real-time frequency tracking technology in vibration-assisted machining systems due to the high loads involved in the machining process. Therefore, an inevitable trend has been to improve resonant vibration systems to adapt to large loads and frequency drift. At present, ultrasonic resonance devices are basically set at the cutter side because of the unpredictable mass and size of workpieces, which further affects amplitude and frequency of the resonant vibration. Nevertheless, the resonant state of the ultrasonic system is greatly influenced by the factors such as tool materials and clamping mode. Meanwhile, besides high-frequency ultrasonic vibration, high cutting loads are also applied directly to the cutter, which leads to high standard requirement of cutting tool [101]. Accordingly, one of the most important trends in resonant vibration-assisted machining systems is improvement in the system and the development of special tools. By taking into account the characteristics of ultrasonic vibration cutting and the integration of cutting tool and ultrasonic vibration system from the perspective of integrated collaborative design, tools can be adapted to the vibration system while meeting the processing requirements, which further ensures the stability of the resonant vibration system. In addition, the issue of overheating in ultrasonic vibration systems operating for long periods is also a problem which needs on urgent solution. Designing a dedicated vibration system with an internal cooling function will help to solve this problem.

As reviewed in the previous section, 2D vibration-assisted machining systems are the most common type of nonresonant vibration system, and these systems are always built using piezoelectric actuators to drive the flexible hinges directly. In addition, most flexible hinge structures are designed to be symmetrical and the current effort in performance improvement of non-resonant vibration-assisted machining systems is mainly focused on the optimization of shape, which limits improvements in performance. For serial flexible hinge structures in non-resonant vibration system, the main drawbacks are the accumulation of vibration error, low working frequency bandwidth, and structural redundancy. For parallel flexible hinge structures in non-resonant vibration systems, the coupling effect between different axes is unavoidable, which seriously affects the motion accuracy of the system and can induce shear stress inside the piezoelectric actuators
Fig. 34 SEM images of burr-free structures made using 2D VAM. Single-crystal diamond tool in hard-plated copper. a Microchannel, $1.5 \mu \mathrm{m}$ deep (b) $8 \mu \mathrm{m}$ tall regular trihedron made using dead-sharp tool with $70^{\circ}$ nose angle [17] (a)

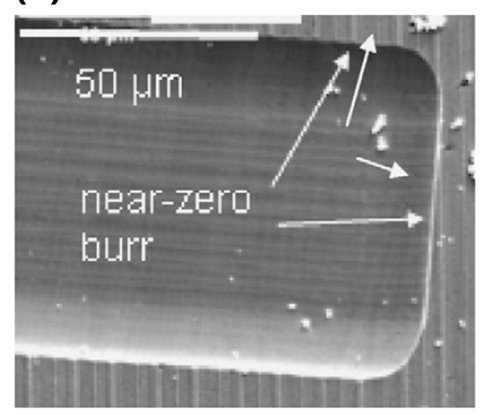

(b)

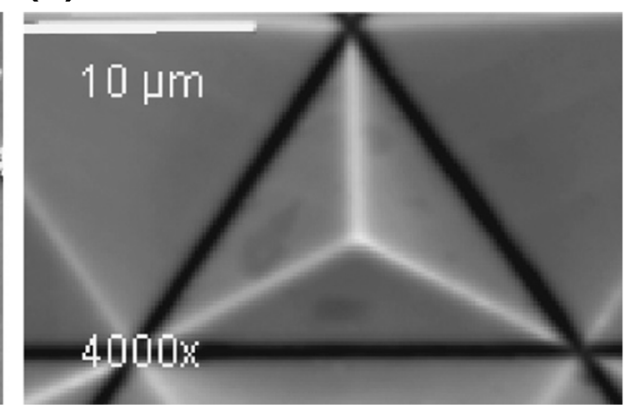


(d)
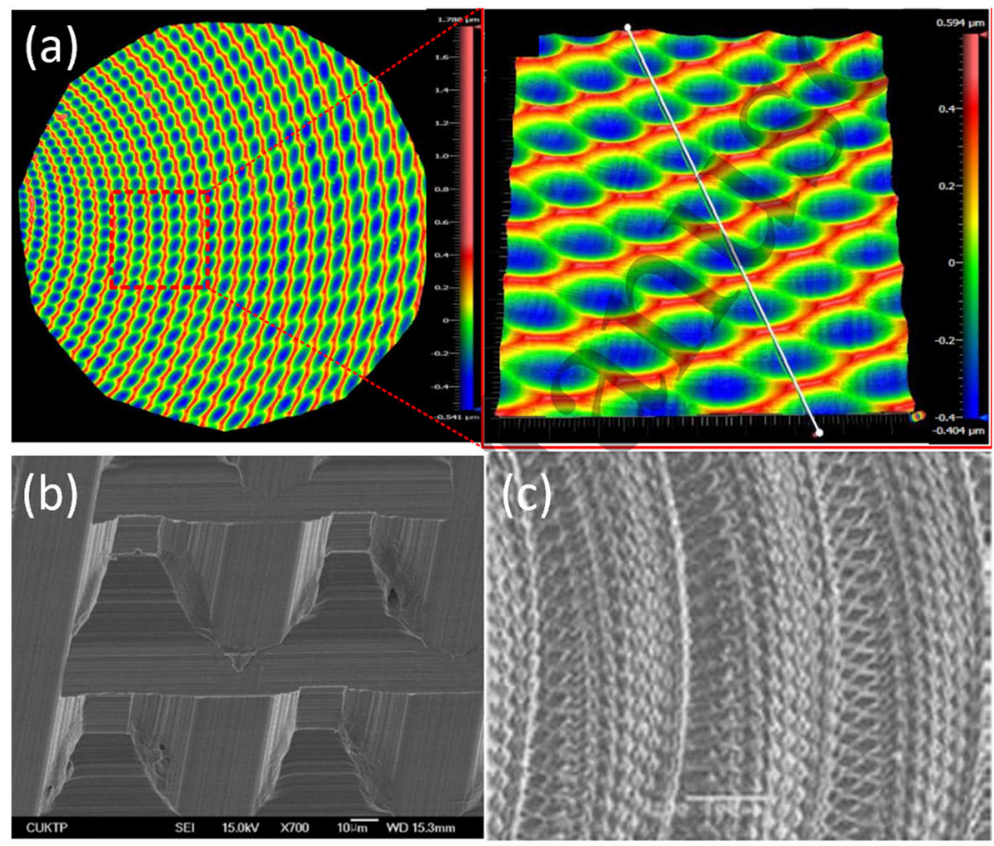
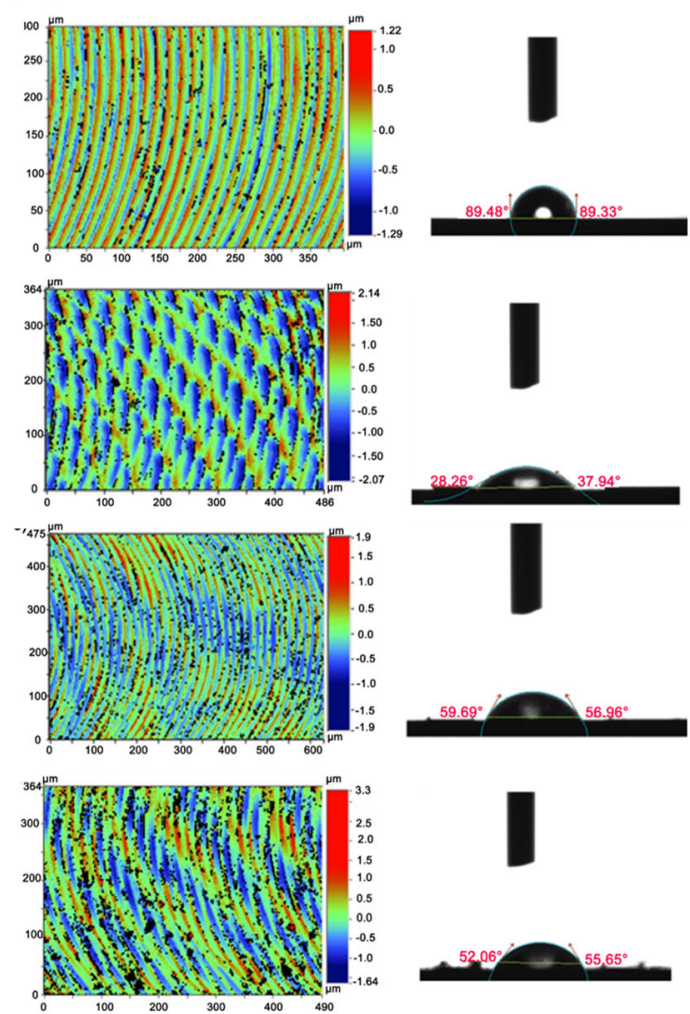
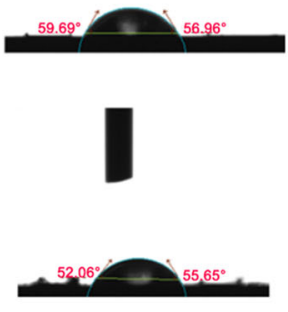

Fig. 35 Surface texture produced by vibration-assisted machining (a) micro-dimple patterns [84], (b) micro-convex patterns [63], (c) squamous patterns [100], and (d) surface wettability variation with different surface texture [75]

and damage them. Therefore, structural optimization of nonresonant vibration systems so as to improve vibration accuracy and reduce coupling effect is a major development trend.

Currently, vibration-assisted machine tools for difficult-tomachine materials have not yet reached maturity. The reliability of the machine tool system and stability in long-term operation need to be evaluated and strengthened. Many sectors such as the aerospace and medical areas have high demand for stable ultrasonic-assisted machine tools. Hence, integrating current research results for ultrasonic vibration-assisted technology and the development of special ultrasonic vibration auxiliary equipment will soon become an important research priorities.

\section{Concluding remarks}

From ongoing in-depth research, more of the merits of vibration-assisted machining are being discovered, which extends its application in precision machining processes with hard and brittle materials. However, well-designed vibration devices are required to ensure their performance. And the strengths and weaknesses of resonant and non-resonant vibration systems are summarised Table 1.

In general, design should consider not only the operating frequency and amplitude, but also the accuracy, ease of control, and application environment. This paper has critically reviewed

Table 1 Strengths and weaknesses of resonant and non-resonant vibration systems

\begin{tabular}{|c|c|c|}
\hline $\begin{array}{l}\text { Classification } \\
\text { Working } \\
\text { principle }\end{array}$ & $\begin{array}{l}\text { Resonant systems } \\
\text { Resonant vibration }\end{array}$ & $\begin{array}{l}\text { Non-resonant systems } \\
\text { Forced vibration }\end{array}$ \\
\hline Strengths & $\begin{array}{l}\text { 1. Usually works at high (ultrasound) vibration frequency, } \\
\text { which benefits to hard and brittle materials processing. } \\
\text { 2. Simple structure in } 1 \mathrm{D} \text { vibration devices. }\end{array}$ & $\begin{array}{l}\text { 1. Changeable vibration frequency and amplitude. } \\
\text { 2. Close-loop control is available to obtain higher motion } \\
\text { accuracy. }\end{array}$ \\
\hline Weaknesses & $\begin{array}{l}\text { 1. It can only work at fixed vibration frequency (system natural } \\
\text { frequency) to achieve enough vibration amplitude. } \\
\text { 2. Close-loop control is hard to achieve due to } \\
\text { high working frequency. }\end{array}$ & $\begin{array}{l}\text { 1. Coupling effect in } 2 \mathrm{D} / 3 \mathrm{D} \text { system cannot be eliminated, } \\
\text { which influences its motion accuracy. } \\
\text { 2. Complex mechanical structures usually } \\
\text { required in } 2 \mathrm{D} / 3 \mathrm{D} \text { systems to reduce coupling effect. }\end{array}$ \\
\hline
\end{tabular}


research and developments in vibration devices. It provides a discussion of both the advantages and disadvantages of existing vibration devices and gives insights into vibration device design in the future. The following are the key observations and suggestion for future work on vibration devices:

1. Vibration-assisted machining has been in development for about 60 years since it was first proposed. Advantages such as extended tool life and better surface finishes have been discovered and have played an important role in improving the machining accuracy of hard and brittle materials and reducing costs. The sources of vibration have undergone on evolution from electro-hydraulic actuators to electromagnetic actuators to piezoelectric actuators, and each evolution improves the motion accuracy of the vibration system.

2. Resonant vibration devices usually vibrate at their natural frequency, and the vibration frequency and amplitude are fixed at certain values. Given the high demand for the precision machining of hard and brittle materials, high vibration frequency, low amplitude, and the undertaking of large loads will be development trends for resonant vibration devices in the near future.

3. The applications of non-resonant vibration systems are more flexible compared with resonant systems due to the variable vibration amplitudes and frequencies. Besides pursuing a wider range of working frequencies and amplitudes, a reduction in the coupling effect is also a significant mainstream research aim with this type of vibration device.

Funding information The authors gratefully acknowledge financial support of the Engineering and Physical Sciences Research Council (EP/ M020657/1).

Open Access This article is licensed under a Creative Commons Attribution 4.0 International License, which permits use, sharing, adaptation, distribution and reproduction in any medium or format, as long as you give appropriate credit to the original author(s) and the source, provide a link to the Creative Commons licence, and indicate if changes were made. The images or other third party material in this article are included in the article's Creative Commons licence, unless indicated otherwise in a credit line to the material. If material is not included in the article's Creative Commons licence and your intended use is not permitted by statutory regulation or exceeds the permitted use, you will need to obtain permission directly from the copyright holder. To view a copy of this licence, visit http://creativecommons.org/licenses/by/4.0/.

\section{References}

1. Sinn G, Zettl B, Mayer H, Stanzl-Tschegg S (2005) Ultrasonicassisted cutting of wood. J Mater Process Technol 170:42-49. https://doi.org/10.1016/j.jmatprotec.2005.04.076

2. Shen XH, Zhang JH, Yin TJ, Dong CJ (2010) A study on cutting force in micro end milling with ultrasonic vibration. Adv Mater Res 97-101:1910-1914. https://doi.org/10.4028/www.scientific. net/AMR.97-101.1910

3. Adnan AS, Subbiah S (2010) Experimental investigation of transverse vibration-assisted orthogonal cutting of AL-2024. Int J
Mach Tools Manuf 50:294-302. https://doi.org/10.1016/j. ijmachtools.2009.11.004

4. Zhong ZW, Lin G (2006) Ultrasonic assisted turning of an aluminium-based metal matrix composite reinforced with SiC particles. Int J Adv Manuf Technol 27:1077-1081. https://doi.org/10. 1007/s00170-004-2320-3

5. Shen XH, Zhang J, Xing DX, Zhao Y (2012) A study of surface roughness variation in ultrasonic vibration-assisted milling. Int $\mathrm{J} \mathrm{Adv}$ Manuf Technol 58:553-561. https://doi.org/10.1007/s00170-0113399-y

6. Nath C, Rahman M (2008) Effect of machining parameters in ultrasonic vibration cutting. Int J Mach Tools Manuf 48:965974. https://doi.org/10.1016/j.ijmachtools.2008.01.013

7. Liu K, Li XP, Rahman M, Liu XD (2004) A study of the cutting modes in the grooving of tungsten carbide. Int $\mathrm{J}$ Adv Manuf Technol 24:321-326. https://doi.org/10.1007/s00170-003-1565-6

8. Liu K, Li XP, Rahman M, Liu XD (2004) Study of ductile mode cutting in grooving of tungsten carbide with and without ultrasonic vibration assistance. Int J Adv Manuf Technol 24:389-394. https://doi.org/10.1007/s00170-003-1647-5

9. Bansevicius R, Tolocka RT (2002) Piezoelectric actuators. In: Mechatronics Handbook

10. Crawley EF, De Luis J (1987) Use of piezoelectric actuators as elements of intelligent structures. AIAA J. https://doi.org/10.2514/ 3.9792

11. Geoffrey B, Winston AK (1989) Fundamentals of machining and machine tools. https://doi.org/10.1007/978-1-84800-213-5

12. Thoe TB (1998) Review on ultrasonic machining.pdf 38:239-255

13. Wang G, Zhou X, Ma P, Wang R, Meng G, Yang X (2018) A novel vibration assisted polishing device based on the flexural mechanism driven by the piezoelectric actuators. AIP Adv 8 . https://doi.org/10.1063/1.5009027

14. Kuhnen K (2003) Modeling, identification and compensation of complex hysteretic nonlinearities: a modified prandtl-ishlinskii approach. Eur J Control. https://doi.org/10.3166/ejc.9.407-418

15. Moheimani SOR, Vautier BJG (2005) Resonant control of structural vibration using charge-driven piezoelectric actuators. IEEE Trans Control Syst Technol 13:1021-1035. https://doi.org/10. 1109/TCST.2005.857407

16. Al-Bender F, Lampaert V, Swevers J (2005) The generalized Maxwell-slip model: a novel model for friction simulation and compensation. IEEE Trans Autom Control. https://doi.org/10. 1109/TAC.2005.858676

17. Brehl DE, Dow TA (2008) Review of vibration-assisted machining. Precis Eng 32:153-172. https://doi.org/10.1016/j. precisioneng.2007.08.003

18. Kumar S, Wu CS, Padhy GK, Ding W (2017) Application of ultrasonic vibrations in welding and metal processing: a status review. J Manuf Process 26:295-322. https://doi.org/10.1016/j.jmapro.2017. 02.027

19. Amin SG, Ahmed MHM, Youssef HA (1995) Computer-aided design of acoustic horns for ultrasonic machining using finiteelement analysis. J Mater Process Technol 55:254-260. https:// doi.org/10.1016/0924-0136(95)02015-2

20. Ostasevicius V, Gaidys R, Dauksevicius R, Mikuckyte S (2013) Study of vibration milling for improving surface finish of difficultto-cut materials. Stroj Vestn-J Mech E 59:351-357. https://doi. org $/ 10.5545 /$ sv-jme.2012.856

21. Alam K, Mitrofanov AV, Silberschmidt VV (2011) Experimental investigations of forces and torque in conventional and ultrasonically-assisted drilling of cortical bone. Med Eng Phys 33:234-239. https://doi.org/10.1016/j.medengphy.2010.10.003

22. Kuo KL (2008) Design of rotary ultrasonic milling tool using FEM simulation. J Mater Process Technol 201:48-52. https:// doi.org/10.1016/j.jmatprotec.2007.11.289 
23. Roy S (2017) Design of a circular hollow ultrasonic horn for USM using finite element analysis:319-328. https://doi.org/10.1007/ s00170-016-8985-6

24. Babitsky VI, Astashev VK, Meadows A (2007) Vibration excitation and energy transfer during ultrasonically assisted drilling. J Sound Vib 308:805-814. https://doi.org/10.1016/j.jsv.2007.03. 064

25. Hsu CY, Huang CK, Wu CY (2007) Milling of MAR-M247 nickel-based superalloy with high temperature and ultrasonic aiding. Int J Adv Manuf Technol 34:857-866. https://doi.org/10.1007/ s00170-006-0657-5

26. N N (1995) Ultrasonic Elliptical Vibration Cutting. https://doi.org/ 10.1016/S0007-8506(07)62269-0

27. Shamoto E, Suzuki N, Moriwaki T, Naoi Y (2002) Development of ultrasonic elliptical vibration controller for elliptical vibration cutting. CIRP Ann Manuf Technol 51:327-330. https://doi.org/ 10.1016/S0007-8506(07)61528-5

28. Shamoto E, Moriwaki T (1999) Ultraprecision diamond cutting of hardened steel by applying elliptical vibration cutting. CIRP Ann. - Manuf. Technol. 48:441-444. https://doi.org/10.1016/S00078506(07)63222-3

29. Liang Z, Wang X, Zhao W, Wu Y, Sato T, Lin W (2010) A feasibility study on elliptical ultrasonic assisted grinding of sapphire substrate. Int J Abras Technol 3:190-202. https://doi.org/10. 1504/IJAT.2010.03405

30. Liang Z, Wang X, Wu Y, Xie L, Jiao L, Zhao W (2013) Experimental study on brittle-ductile transition in elliptical ultrasonic assisted grinding (EUAG) of monocrystal sapphire using single diamond abrasive grain. Int J Mach Tools Manuf 71:4151. https://doi.org/10.1016/j.ijmachtools.2013.04.004

31. Peng Y, Liang Z, Wu Y, Guo Y, Wang C (2012) Characteristics of chip generation by vertical elliptic ultrasonic vibration-assisted grinding of brittle materials. Int J Adv Manuf Technol 62:563568. https://doi.org/10.1007/s00170-011-3839-8

32. Liu J, Zhang D, Qin L, Yan L (2012) Feasibility study of the rotary ultrasonic elliptical machining of carbon fiber reinforced plastics (CFRP). Int J Mach Tools Manuf 53:141-150. https://doi.org/10. 1016/j.ijmachtools.2011.10.007

33. Geng D, Zhang D, Xu Y, He F, Liu D, Duan Z (2015) Rotary ultrasonic elliptical machining for side milling of CFRP: tool performance and surface integrity. Ultrasonics. 59:128-137. https:// doi.org/10.1016/j.ultras.2015.02.006

34. Suzuki N, Yan Z, Hino R, Shamoto E, Hirahara Y, Imasuda T (2006) Ultraprecision micro-machining of single crystal germanium by applying elliptical vibratlon cutting. In: 2006 IEEE Int. Symp. Micro-Nano Mech. Hum. Sci. MHS. https://doi.org/10. 1109/MHS.2006.320323

35. Suzuki N, Haritani M, Yang J, Hino R, Shamoto E (2007) Elliptical vibration cutting of tungsten alloy molds for optical glass parts. CIRP Ann Manuf Technol 56:127-130. https://doi. org/10.1016/j.cirp.2007.05.032

36. Suzuki H, Hamada S, Okino T, Kondo M, Yamagata Y, Higuchi T (2010) Ultraprecision finishing of micro-aspheric surface by ultrasonic two-axis vibration assisted polishing. CIRP Ann. - Manuf. Technol. 59:347-350. https://doi.org/10.1016/j.cirp.2010.03.117

37. Li X, Zhang D (2006) Ultrasonic elliptical vibration transducer driven by single actuator and its application in precision cutting. J Mater Process Technol 180:91-95. https://doi.org/10.1016/j. jmatprotec.2006.05.007

38. Yin Z, Fu Y, Li H, Cao Z, Chen Y (2017) Mathematical modeling and experimental verification of a novel single-actuated ultrasonic elliptical vibrator. Adv Mech Eng 9:1-12. https://doi.org/10.1177/ 1687814017745413

39. Yin Z, Fu Y, Xu J, Li H, Cao Z, Chen Y (2017) A novel single driven ultrasonic elliptical vibration cutting device. Int $\mathrm{J}$ Adv
Manuf Technol 90:3289-3300. https://doi.org/10.1007/s00170016-9641-X

40. Börner R, Winkler S, Junge T, Titsch C, Schubert A, Drossel WG (2018) Generation of functional surfaces by using a simulation tool for surface prediction and micro structuring of cold-working steel with ultrasonic vibration assisted face milling. J Mater Process Technol 255:749-759. https://doi.org/10.1016/j.jmatprotec.2018.01. 027

41. Tan R, Zhao X, Zou X, Sun T (2018) A novel ultrasonic elliptical vibration cutting device based on a sandwiched and symmetrical structure. Int J Adv Manuf Technol 97:1397-1406. https://doi.org/ 10.1007/s00170-018-2015-9

42. Guo J, Suzuki H, Morita S-Y, Yamagata Y, Higuchi T (2012) Micro polishing of tungsten carbide using magnetostrictive vibrating polisher. Key Eng Mater 516:569-574. https://doi.org/10. 4028/www.scientific.net/KEM.516.569

43. Guo J, Morita SY, Hara M, Yamagata Y, Higuchi T (2012) Ultraprecision finishing of micro-aspheric mold using a magnetostrictive vibrating polisher. CIRP Ann. - Manuf. Technol. 61:371-374. https://doi.org/10.1016/j.cirp.2012.03.141

44. Guo J, Suzuki H, Higuchi T (2013) Development of micro polishing system using a magnetostrictive vibrating polisher. Precis Eng 37:81-87. https://doi.org/10.1016/j.precisioneng. 2012.07.003

45. Asumi K, Fukunaga R, Fujimura T, Kurosawa MK (2009) Miniaturization of a V-shape transducer ultrasonic motor. Jpn J Appl Phys 48:07GM02. https://doi.org/10.1143/JJAP.48. 07GM02

46. Zhang F, Chen W, Liu J, Wang Z (2005) Bidirectional linear ultrasonic motor using longitudinal vibrating transducers. IEEE Trans Ultrason Ferroelectr Freq Control 52:134-138. https://doi. org/10.1109/TUFFC.2005.1397358

47. Kurosawa MK, Kodaira O, Tsuchitoi Y, Higuchi T (1998) Transducer for high speed and large thrust ultrasonic linear motor using two sandwich-type vibrators. IEEE Trans Ultrason Ferroelectr Freq Control 45:1188-1195. https://doi.org/10.1109/ 58.726442

48. Guo P, Ehmann KF (2013) Development of a tertiary motion generator for elliptical vibration texturing. Precis Eng 37:364 371. https://doi.org/10.1016/j.precisioneng.2012.10.005

49. Song D, Zhao J, Ji S, Zhou X (2016) Development of a novel twodimensional ultrasonically actuated polishing process. AIP Adv 6 . https://doi.org/10.1063/1.4967292

50. Yanyan Y, Bo Z, Junli L (2009) Ultraprecision surface finishing of nano- $\mathrm{ZrO} 2$ ceramics using two-dimensional ultrasonic assisted grinding. Int J Adv Manuf Technol 43:462-467. https://doi.org/ 10.1007/s00170-008-1732-x

51. Suzuki N, Hino R, Shamoto E (2007) Development of 3 DOF ultrasonic elliptical vibration system for elliptical vibration cutting. In Proceedings of ASPE Spring Topical Meeting on Vibration Assisted Machining Technology (pp. 15-20). http:// www.aspe.net/publications/Spring_2007/Spr07Ab/2156-Suzuki. pdf

52. Shamoto E, Suzuki N, Tsuchiya E, Hori Y, Inagaki H, Yoshino K (2005) Development of 3 DOF ultrasonic vibration tool for elliptical vibration cutting of sculptured surfaces. CIRP Ann Manuf Technol. https://doi.org/10.1016/S0007-8506(07)60113-9

53. Shamoto E, Suzuki N, Hino R, Tsuchiya E, Hori Y, Inagaki H, Yoshino K (2005) A new method to machine sculptured surfaces by applying ultrasonic elliptical vibration cutting. In: Proc. 2005 Int. Symp. Micro-NanoMechatronics Hum. Sci. Eighth Symp. Micro- Nano-Mechatronics Information-Based Soc. - 21st Century COE Progr. https://doi.org/10.1109/MHS.2005.1589969

54. Lee DY, Kim DM, Gweon DG, Park J (2007) A calibrated atomic force microscope using an orthogonal scanner and a calibrated 
laser interferometer. Appl Surf Sci 253:3945-3951. https://doi. org/10.1016/j.apsusc.2006.08.027

55. Syahputra HP, Ko TJ, Chung BM (2014) Development of 2-axis hybrid positioning system for precision contouring on micromilling operation. J Mech Sci Technol 28:691-697. https://doi. org/10.1007/s12206-013-1132-5

56. Kurniawan R, Ko TJ, Ping LC, Kumaran ST, Kiswanto G, Guo P, Ehmann KF (2017) Development of a two-frequency, ellipticalvibration texturing device for surface texturing. J Mech Sci Technol 31:3465-3473. https://doi.org/10.1007/s12206-017-0635$\mathrm{x}$

57. Greco A, Raphaelson S, Ehmann K, Wang QJ, Lin C (2009) Surface texturing of tribological interfaces using the vibromechanical texturing method. J Manuf Sci Eng 131: 061005. https://doi.org/10.1115/1.4000418

58. Hong MS, Ehmann KF (1995) Generation of engineered surfaces by the surface-shaping system. Int J Mach Tools Manuf 35:12691290. https://doi.org/10.1016/0890-6955(94)00114-Y

59. Suzuki H, Marshall MB, Sims ND, Dwyer-Joyce RS (2017) Design and implementation of a non-resonant vibration-assisted machining device to create bespoke surface textures. Proc Inst Mech Eng C J Mech Eng Sci 231:860-875. https://doi.org/10. $1177 / 0954406215625087$

60. Wang G (2001) Elliptical diamond milling: kinematics, force and tool wear. North Carolina State University http://repository.lib. ncsu.edu/ir/handle/1840.16/2454

61. Brehl DE, Dow TA, Garrard K, Sohn A, Carolina N (2006) Micro-structure fabrication using elliptical vibration- assisted machining ( Evam ) 1. Proc. 21th Annu. ASPE Meet. 511-514

62. Cerniway M (2001) Elliptical diamond milling: kinematics, force and tool wear. North Carolina State University

63. Kim GD, Loh BG (2010) Machining of micro-channels and pyramid patterns using elliptical vibration cutting. Int J Adv Manuf Technol 49:961-968. https://doi.org/10.1007/s00170-009-2451-7

64. Kim GD, Loh BG (2007) An ultrasonic elliptical vibration cutting device for micro V-groove machining: kinematical analysis and micro V-groove machining characteristics. J Mater Process Technol 190:181-188. https://doi.org/10.1016/j.jmatprotec.2007. 02.047

65. Kim GD, Loh BG (2007) Characteristics of chip formation in micro V-grooving using elliptical vibration cutting. J Micromech Microeng 17:1458-1466. https://doi.org/10.1088/0960-1317/17/8/007

66. Li G, Wang B, Xue J, Qu D, Zhang P (2018) Development of vibration-assisted micro-milling device and effect of vibration parameters on surface quality and exit-burr. Proc Inst Mech Eng B J Eng Manuf:095440541877459. https://doi.org/10.1177/ 0954405418774592

67. Loh BG, Kim GD (2012) Correcting distortion and rotation direction of an elliptical trajectory in elliptical vibration cutting by modulating phase and relative magnitude of the sinusoidal excitation voltages. Proc Inst Mech Eng B J Eng Manuf 226:813-823. https://doi.org/10.1177/0954405411431375

68. Ahn J, Lim H, Son S (1999) Improvement of micro-machining accuracy by 2-dimensional vibration cutting. Proc ASPE (Vol. 20, pp. 150-153) http://aspe.net:16080/publications/Annual_1999/ POSTERS/PROCESS/NONCONV/AHN.PDF

69. Chern GL, Chang YC (2006) Using two-dimensional vibration cutting for micro-milling. Int J Mach Tools Manuf 46:659-666. https://doi.org/10.1016/j.ijmachtools.2005.07.006

70. Jin X, Xie B (2015) Experimental study on surface generation in vibration-assisted micro-milling of glass. Int J Adv Manuf Technol 81:507-512. https://doi.org/10.1007/s00170-015-7211-2

71. Ding H, Chen SJ, Cheng K (2010) Two-dimensional vibrationassisted micro end milling: cutting force modelling and machining process dynamics. Proc Inst Mech Eng B J Eng Manuf 224:17751783. https://doi.org/10.1243/09544054JEM1984
72. Ding H, Chen SJ, Cheng K (2011) Dynamic surface generation modeling of two-dimensional vibration-assisted micro-end-milling. Int J Adv Manuf Technol 53:1075-1079. https://doi.org/10. 1007/s00170-010-2903-0

73. LiGuo (2012) Non-resonant vibration auxiliary table development and study on micro-milling technology experiment, $\mathrm{PhD}$ Thesis Harbin Institute of Technology

74. Zhang J, Sun B (2006) Design and analysis of 2-DOF nanopositioning stage based on dual flexure hinges. Piezoelectrics and Acoustooptics 28:624-626. http://en.cnki. com.cn/Article en/CJFDTotal-YDSG200605041.htm

75. Zheng L, Chen W, Pozzi M, Teng X, Huo D (2018) Modulation of surface wettability by vibration assisted milling. Precis Eng 55:110. https://doi.org/10.1016/j.precisioneng.2018.09.006

76. Zheng L, Chen W, Huo D (2018) Experimental investigation on burr formation in vibration-assisted micro-milling of Ti-6Al-4V. Proc Inst Mech Eng C J Mech Eng Sci 233:4112-4119. https:// doi.org/10.1177/0954406218792360095440621879236

77. Chen W, Zheng L, Huo D (2018) Surface texture formation by non-resonant vibration assisted micro milling. J Micromech Microeng. 28(2):025006. https://iopscience.iop.org/article/10. 1088/1361-6439/aaa06f/meta

78. Zheng L, Chen W, Huo D, Lyu X (2020) Design, analysis and control of a $2 \mathrm{D}$ vibration device for vibration assisted micro milling. IEEE/ASME Trans Mechatronics 4435:1-1. https://doi.org/ 10.1109/tmech.2020.2978209

79. Zheng L, Chen W, Huo D (2020) Investigation on the tool Wear suppression mechanism in non-resonant vibration-assisted micro milling. Micromachines. https://doi.org/10.3390/mi11040380

80. Ibrahim R (2010) Vibration assisted machining: modelling. Simulation, Optimization, Control and Applications, School of Engineering and Design Brunel University. https://bura.brunel. ac.uk/handle/2438/4732

81. Ding H, Chen SJ, Ibrahim R, Cheng K (2011) Investigation of the size effect on burr formation in two-dimensional vibration-assisted micro end milling. Proc Inst Mech Eng B J Eng Manuf 225:20322039. https://doi.org/10.1177/0954405411400820

82. Liu Y (2015) The non-resonant elliptical vibration turning of microstructure surface. Jilin University. http://cdmd.cnki.com.cn/ Article/CDMD-10183-1015591770.htm

83. Kim HS, Kim SI, Il Lee K, Lee DH, Bang YB, Il Lee K (2009) Development of a programmable vibration cutting tool for diamond turning of hardened mold steels. Int J Adv Manuf Technol 40:26-40. https://doi.org/10.1007/s00170-007-1311-6

84. Lin J, Han J, Lu M, Yu B, Gu Y (2017) Design, analysis and testing of a new piezoelectric tool actuator for elliptical vibration turning. Smart Mater Struct 26:085008. https://doi.org/10.1088/ 1361-665x/aa71f0

85. Chee SK, Suzuki H, Okada M, Yano T, Higuchi T, Lin W (2011) Precision polishing of micro mold by using piezoelectric actuator incorporated with mechanical amplitude magnified mechanism. Adv Mater Res 325:470-475. https://doi.org/10.4028/www. scientific.net/AMR.325.470

86. Chee SK, Suzuki H, Uehara J, Yano T, Higuchi T, Lin W (2013) A low contact force polishing system for micro molds that utilizes 2-dimensional low frequency vibrations (2DLFV) with piezoelectric actuators (PZT) and a mechanical transformer mechanism. Int J Autom Technol 7:71-82

87. Jieqiong L, Yingchun L, Xiaoqin Z (2014) Tool path generation for fabricating optical freeform surfaces by non-resonant threedimensional elliptical vibration cutting. Proc Inst Mech Eng C J Mech Eng Sci 228:1208-1222. https://doi.org/10.1177/ 0954406213502448

88. Li Y, Xu Q (2011) A totally decoupled piezo-driven XYZ flexure parallel micropositioning stage for micro/nanomanipulation. IEEE 
Trans Autom Sci Eng 8:265-279. https://doi.org/10.1109/TASE. 2010.2077675

89. Wang G (2012) Development of a three-dimentional elliptical vibration assisted diamond cutting apparatus. Jilin University. http://cdmd.cnki.com.cn/Article/CDMD-10183-1012368757.htm

90. Liu P (2013) Development of a new apparatus for threedimensional elliptical vibration cutting. Jilin University. http:// cdmd.cnki.com.cn/Article/CDMD-10183-1013194433.htm

91. Zhu Z, S. To, Ehmann KF, Zhou X (2017) Design, analysis, and realization of a novel piezoelectrically actuated rotary spatial vibration system for micro-/nanomachining. IEEE/ASME Trans Mechatronics 22:1227-1237. https://doi.org/10.1109/TMECH. 2017.2682983

92. Lin J, Lu M, Zhou X (2016) Development of a non-resonant 3D elliptical vibration cutting apparatus for diamond turning. Exp Tech 40:173-183. https://doi.org/10.1007/s40799-016-0021-0

93. Lu M (2014) Development of 3D elliptical vibration assisted cutting appratus and its control. Jilin University. http://cdmd.cnki. com.cn/Article/CDMD-10183-1014268066.htm

94. Zhang J, Suzuki N, Wang Y, Shamoto E (2014) Fundamental investigation of ultra-precision ductile machining of tungsten carbide by applying elliptical vibration cutting with single crystal diamond. J Mater Process Technol 214:2644-2659. https://doi. org/10.1016/j.jmatprotec.2014.05.024

95. Du Kim J, Choi IH (1997) Micro surface phenomenon of ductile cutting in the ultrasonic vibration cutting of optical plastics. J
Mater Process Technol 68:89-98. https://doi.org/10.1016/S09240136(96)02546-0

96. Zhou M, Wang XJ, Ngoi BKA, Gan JGK (2002) Brittle-ductile transition in the diamond cutting of glasses with the aid of ultrasonic vibration. J Mater Process Technol 121:243-251. https://doi. org/10.1016/S0924-0136(01)01262-6

97. Chang SSF, Bone GM (2010) Burr height model for vibration assisted drilling of aluminum 6061-T6. Precis Eng 34:369-375. https://doi.org/10.1016/j.precisioneng.2009.09.002

98. Chang SSF, Bone GM (2005) Burr size reduction in drilling by ultrasonic assistance. Robot Comput Integr Manuf. https://doi.org/ 10.1016/j.rcim.2004.11.005

99. Brehl DE, Dow TA, Garrard K, Sohn A (2006) Micro-structure fabrication using elliptical vibration-assisted machining (EVAM). In: Proc. 21st Annu. ASPE meet. ASPE 2006

100. Tao G, Ma C, Bai L, Shen X, Zhang J (2017) Feed-direction ultrasonic vibration-assisted milling surface texture formation. Mater Manuf Process 32:193-198. https://doi.org/10.1080/ 10426914.2016.1198029

101. Zhang Y, Kang R, Liu J, Zhang Y, Zheng W, Dong Z (2017) Review of ultrasonic vibration assisted drilling. J Mech Eng 53. https://doi.org/10.3901/JME.2017.19.033

Publisher's note Springer Nature remains neutral with regard to jurisdictional claims in published maps and institutional affiliations. 